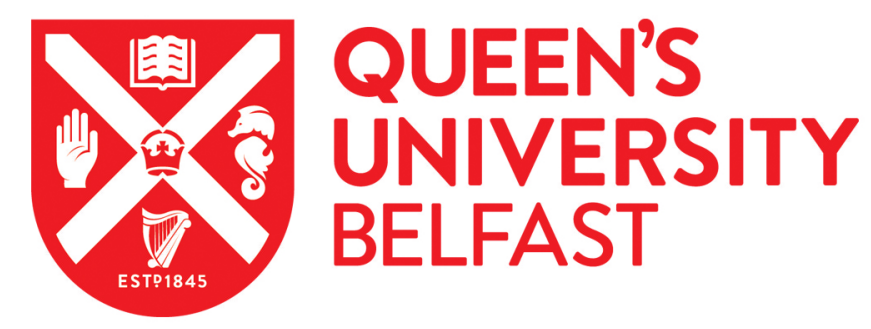

\title{
Ubiquity of polystyrene digestion and biodegradation within yellow mealworms, larvae of Tenebrio molitor Linnaeus (Coleoptera: Tenebrionidae)
}

Shan, M. H., Yang, S., Wu, W-M., Fan, H-Q., Brandon, A. M., Receveur, J., Li, Y., Fan, R., Wang, Z-Y., Gao, SH., McClellan, R., Daliang, N., Phillips, D., Wang, H., Peng, B-Y., Li, P., Cai, S-Y., Ding, L-Y., Cai, W-W., Criddle, C. (2018). Ubiquity of polystyrene digestion and biodegradation within yellow mealworms, larvae of Tenebrio molitor Linnaeus (Coleoptera: Tenebrionidae). Chemosphere, 262-272. https://doi.org/10.1016/j.chemosphere.2018.08.078

Published in:

Chemosphere

Document Version:

Peer reviewed version

Queen's University Belfast - Research Portal:

Link to publication record in Queen's University Belfast Research Portal

\section{Publisher rights}

Copyright 2018 Elsevier.

This manuscript is distributed under a Creative Commons Attribution-NonCommercial-NoDerivs License

(https://creativecommons.org/licenses/by-nc-nd/4.0/), which permits distribution and reproduction for non-commercial purposes, provided the author and source are cited.

\section{General rights}

Copyright for the publications made accessible via the Queen's University Belfast Research Portal is retained by the author(s) and / or other copyright owners and it is a condition of accessing these publications that users recognise and abide by the legal requirements associated with these rights.

\section{Take down policy}

The Research Portal is Queen's institutional repository that provides access to Queen's research output. Every effort has been made to ensure that content in the Research Portal does not infringe any person's rights, or applicable UK laws. If you discover content in the Research Portal that you believe breaches copyright or violates any law, please contact openaccess@qub.ac.uk. 


\title{
Ubiquity of Polystyrene Consumption and Degradation by Mealworms (the larvae of Tenebrio molitor ) from Different Geographic Sources
}

\author{
Shan-Shan Yang ${ }^{1,4}$, Wei-Min Wu* ${ }^{1}$, Anja M. Brandon ${ }^{1}$, Han-Qing Fan ${ }^{1}$, Joe Receveur ${ }^{2}$, Yiran Li ${ }^{1,4}$, \\ Rebecca L. McClellan ${ }^{1}$, Zhi-Yue Wang ${ }^{1}$, Shu-Hong Gao ${ }^{3}$, Daliang Ning ${ }^{3}$, Debra H. Phillips ${ }^{5}$, Bo-Yu \\ Peng ${ }^{6}$, Hongtao Wang ${ }^{6}$, Shen-Yang $\mathrm{Cai}^{6}$, Ping $\mathrm{Li}^{6}$, Wei-Wei Cai ${ }^{7}$, Qin-Qin $\mathrm{Wu}^{8}$, Jie Ren ${ }^{6}$, Ya-Lei \\ Zhang $^{6}$, Jun Yang ${ }^{9}$, Jie Gao ${ }^{10}$, Defeng Xing ${ }^{4}$, Nan-Qi Ren ${ }^{4}$, Robert M. Waymouth ${ }^{1}$, Jizhong Zhou ${ }^{3}$, \\ Hu-Chun $\mathrm{Tao}^{8}$, Eric Benbow ${ }^{2}$, Craig S. Criddle ${ }^{* 1}$
}

${ }^{1}$ Department of Civil and Environmental Engineering, Department of Chemistry, William \& Cloy Codiga Resource Recovery Center, Center for Sustainable Development \& Global Competitiveness, Stanford University, Stanford, CA 94305-4020, USA

, Stanford University, Stanford, CA 94305-4020, USA

${ }^{2}$ Department of Entomology, Department of Osteopathic Medical Specialties, Michigan State University, East Lansing, Michigan 48824, USA

${ }^{3}$ Institute for Environmental Genomics, Department of Microbiology and Plant Biology and School of Civil Engineering and Environmental Sciences, University of Oklahoma, Norman, Oklahoma 73019, USA

${ }^{4}$ State Key Laboratory of Urban Water Resource and Environment, School of Environmental Science and Technology, Harbin Institute of Technology, Harbin 150090, China

${ }^{5}$ School of Natural and Built Environment, Queen's University Belfast, Belfast BT9 5AG, Northern Ireland, U.K.

${ }^{6}$ School of Material Science and Engineering, School of Environmental Science and Engineering, School of Life Science, Tongji University, Shanghai 201804, China

${ }^{7}$ School of Environment and Energy, Peking University Shenzhen Graduate School, Shenzhen 518055, China

${ }^{9}$ School of Chemistry, Beihang University, Beijing 100191, China

${ }^{10}$ Research Center for Eco-Environmental Sciences, Chinese Academy of Sciences, Beijing, 100085, China

\section{AUTHOR INFORMATION}

Corresponding author:

*Telephone: 1-650-724-5310. Email: billwu@ stanford.edu.

*Telephone: 1-650-723-9032. Email: ccriddle@ stanford.edu. 


\section{Abstract}

Academics researchers and "citizen scientists" from 22 countries confirmed that yellow mealworms, the larvae of Tenebrio molitor Linnaeus, can survive by eating polystyrene (PS) foam. More detailed assessments of this capability for mealworms were carried out by 12 sources: five from the USA, six from China, and one from Northern Ireland. All of these mealworms digested PS foam. PS mass decreased and depolymerization was observed, with appearance of lower molecular weight residuals and functional groups indicative of oxidative transformations in extracts from the frass (insect excrement). An addition of gentamycin $\left(30 \mathrm{mg} \mathrm{g}^{-1}\right)$, a bactericidal antibiotic, inhibited depolymerization, implicating the gut microbiome in the biodegradation process. Microbial community analyses demonstrated significant taxonomic shifts for mealworms fed diets of PS plus bran and PS alone. The results indicate that mealworms from diverse locations eat and metabolize PS and support the hypothesis that this capacity is independent of the geographic origin of the mealworms, and is likely ubiquitous to members of this species.

\section{Graphical abstract}

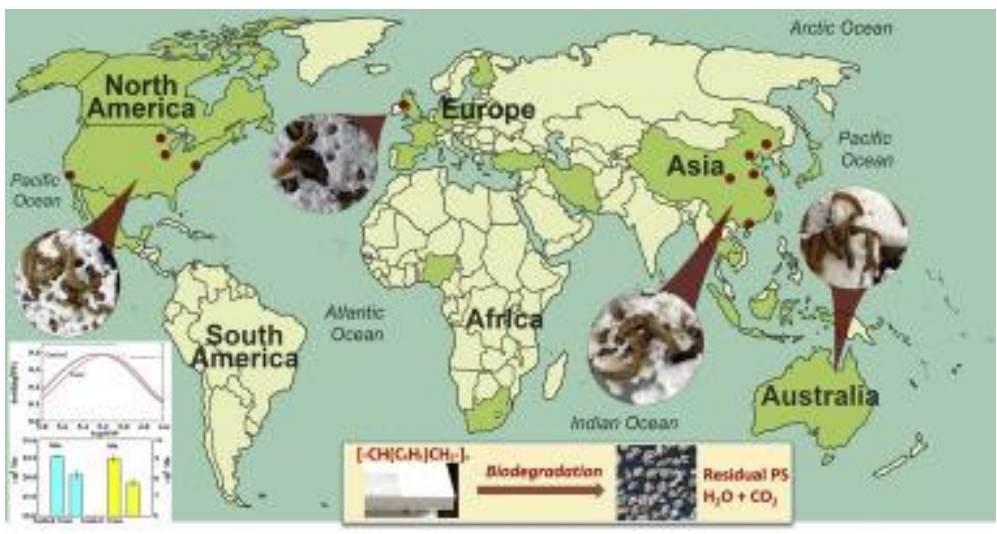

\section{Keywords}

Plastic wastes; Polystyrene; Degradation; Mealworms; Tenebrio molitor; gut microbiome

\section{Introduction}

The accumulation of petroleum-based synthetic plastic wastes, including polystyrene (PS), polyethylene (PE), polypropylene (PP), polyurethane (PUR), polyvinyl chloride (PVC), and polyethylene terephthalate (PET), is a major environmental concern, with up to 6300 million metric tons generated to date (Geyer et al., 2017). Plastic degradation is defined as a physical or chemical change in the polymer due to environmental factors, such as light, heat, moisture, chemical conditions or biological activity (Shah et al., 2008). During microbial biodegradation, polymers are first depolymerized to smaller monomers, which are further degraded for energy or assimilated. 
Ultimate biodegradation or mineralization is achieved when the degraded monomers are converted to $\mathrm{CO}_{2}$, water, and stabilized microbial biomass. Most petroleum-based plastics are resistant to biodegradation (Otake et al., 1995; Shah et al., 2008). One of the most commonly used plastics is PS, ([- $\left.\left.\mathrm{CH}-\left(\mathrm{C}_{6} \mathrm{H}_{5}\right) \mathrm{CH}_{2}-\right]_{\mathrm{n}}\right)$, constituting $7.1 \%$ of annual plastic production (Wu et al., 2017). PS products and materials are used in diverse applications, including eyeglasses frames, plastic cups, egg trays, packaging, and building insulation (Plastics Europe, 2016). Consequently, PS has become a major pollutant of soils, rivers, lakes, and oceans (Zhou et al., 2011) and a source of microplastics ( $<5 \mathrm{~mm}$ ) (Hidalgo-Ruz et al., 2012; Wu et al., 2017). Although resistant to microbial biodegradation in a wide range of habitats (Guillet et al., 1974; Jones et al., 1974; Sielicki et al., 1978; Kaplan et al., 1979; Mor and Sivan, 2008; Råberg and Hafrén, 2008), PS is now known to be susceptible to rapid biodegradation in the gut of yellow mealworms (Yang et al., 2015a, Yang et al., 2018; Brandon et al., 2018), the larval form of Tenebrio molitor Linnaeus (Howard, 1955; Roberson, 2005; Löbl et al., 2008).

T. molitor belongs to the order Coleoptera (beetles) and family Tenebrionidae (common name "darkling beetle"), a cosmopolitan family of beetles with more than 20,000 species. Since the 1950's, researchers have observed that some beetles and larvae in the Tenebrionidae family can damage plastic packaging materials (Gerhardt and Lindgren, 1954; Cline, 1978; Newton, 1988). Subsequently, consumption of PS foams by mealworms was reported by students competing in high school science fairs: in 2003, Ms. Chong-Guan Chen raised mealworms fed PS foam and theorized that the PS biodegraded (Sina, 2003); in 2009, Ms. IChing Tseng isolated bacteria from mealworms gut using PS as the sole carbon source (Burkart, 2009). Convincing academic evidence of PS degradation was reported in mealworms from Beijing, China (Yang et al., 2015a) then in a mealworm strain from a pet store in the United States (Yang et al., 2018). After a 1-2 week adaptation period, the polymer fraction of ingested Styrofoam decreased by up to $65 \%$ with a $12-15 \mathrm{~h}$ gut retention time (Yang et al., 2018). Almost half of the ingested PS carbon was converted into $\mathrm{CO}_{2}$ in the mealworm gut (Yang et al., 2015a; Brandon et al., 2018). Isotopic studies using ${ }^{13} \mathrm{C}$-labeled PS materials have shown that PS was mineralized to ${ }^{13} \mathrm{CO}_{2}$ and incorporated into lipids (Yang et al., 2015a). After being fed with the antibiotic gentamycin, the mealworm strain from Beijing almost completely lost the ability to depolymerize PS and mineralize PS into $\mathrm{CO}_{2}$, implicating gut bacteria in PS biodegradation (Yang et al., 2015b). Additional studies on the same strains of mealworms isolated a PS-degrading bacteria strain (Exiguobacterium sp.) (Yang et al., 2015b) and indicated that co-feeding with bran resulted in enhanced PS degradation and enabled mealworms to consume PS for multiple generations (Yang et al., 2018).

In this study, we test the hypothesis that PS degradation in mealworms is ubiquitous. Evaluation of this hypothesis is needed because prior work has focused on mealworms from 
just two sources (Yang et al., 2015a, Yang et al., 2018). To assess plastic biodegradation for mealworms from a broader range of sources, we enlisted the help of academic and nonacademic institutions from around the world to collect information about mealworm behavior related to plastic consumption. We also obtained mealworms from 12 different sources and tested them for PS degradation using standard protocols (Yang et al., 2015a, Yang et al., 2018), including PS mass balances to determine the specific rates of PS degradation; (2) gel permeation chromatography (GPC) to assess changes in molecular weight, and (3) Fourier transform infrared (FTIR) spectroscopy of frass residues to identify chemical modifications resulting from PS digestion.

We find that mealworms from diverse locations share the ability to consume and degrade PS. We also report observations that add to the existing body of evidence that the gut microbiome plays a role in PS depolymerization and degradation. These microbiomes differ for microorganisms from different sources, with shifts in microbial community structure observed when mealworms are fed PS.

\section{Methods}

\subsection{Worldwide survey}

One of the co-authors (W.-M. Wu, Stanford University) organized and supervised a worldwide survey with volunteer investigators from around world, including middle school and high school students, university students, school teachers, professors, mealworm farmers and mealworm breeders. These diverse collaborators obtained locally available mealworms and fed them PS materials, including Styrofoam, XPS, and other PS foams. Information of the location of the investigator, source of mealworms, test materials and plastic-eating and consumption behavior is summarized in the Supplementary data. Web searches for literature, science fair news and YouTube videos were also used to obtain information on mealworms eating patterns and degradation of PS and other plastics within mealworms.

\subsection{Source of mealworms}

Mealworms (developmental stage: instar 5-7) from the twelve sources (five in the USA, six in China, and one in the United Kingdom) were obtained by: (1) direct purchase from the PetCo Pet Store Chain, Mountain View, California (supplied to the store by Timberline Fisheries); (2) direct purchase from the PetSmart Pet Store Chain, Sunnyvale, California (supplied by Bug Company, Ham Lake, Minnesota); (3) mail order from

Timberline Fisheries, Marion, Illinois (ordered separately from source 1); (4) mail order from Exotic Nutrition Pet Company, Newport News, Virginia; (5) mail order from Rainbow Mealworms, Compton, California; (6) direct purchase from a pet store in Belfast, Northern Ireland, UK; (7) direct purchase from a pet store in Beijing; (8) mail order from a store in 
Harbin, Heilongjiang Province; (9) direct purchase from a mealworm farm in Tai'an County, Shandong Province; (10) direct purchase from a pet store in Xi'an City, Shaanxi Province; (11) direct purchase from a pet store in Shanghai; (12) mail order from and a pet store in Shenzhen City, Guangdong Province (Table 1). All larvae were identified as Tenebrio molitor Linnaeus based on morphology and coloration. Prior to arrival, and for at least two days prior to PS degradation tests, the larvae were fed bran and maintained in incubators with bran.

Table 1. Summary of PS biodegradation studies conducted at Stanford, Belfast and Beijing.

\begin{tabular}{|c|c|c|c|c|c|c|c|}
\hline \multirow{2}{*}{$\begin{array}{l}\text { Mealworm source } \\
\text { (no. mealworms) }\end{array}$} & \multirow{2}{*}{$\begin{array}{l}\text { Initial wt mg } \\
\text { worm }^{-1}\end{array}$} & \multirow[t]{2}{*}{ Feed } & \multirow{2}{*}{$\begin{array}{c}\text { Final } \\
\text { day }\end{array}$} & \multirow{2}{*}{$\begin{array}{l}\text { Final wt mg } \\
\text { worm }^{-1}\end{array}$} & \multirow{2}{*}{$\begin{array}{c}\text { Survival } \\
\text { rate } \%\end{array}$} & \multicolumn{2}{|c|}{ Specific PS consumption rate } \\
\hline & & & & & & $\begin{array}{l}\operatorname{mg} \text { PS } 100 \\
\text { worms }^{-1} d^{-1}\end{array}$ & $\begin{array}{c}\text { mg PS g } \\
\text { worms }^{-1} \mathbf{d}^{-1}\end{array}$ \\
\hline \multirow[t]{2}{*}{1 USA (120) } & \multirow[t]{2}{*}{$76.54 \pm 1.55$} & $\mathrm{PS}+\mathrm{B}$ & 32 & $78.64 \pm 0.42$ & $89.2 \pm 0.8$ & $40.67 \pm 0.95$ & $5.31 \pm 0.12$ \\
\hline & & PS & 32 & $74.77 \pm 0.36$ & $81.7 \pm 0.8$ & $18.74 \pm 0.31$ & $2.44 \pm 0.04$ \\
\hline \multirow[t]{4}{*}{2 USA (120) } & \multirow[t]{4}{*}{$73.98 \pm 0.81$} & $\mathrm{PS}+\mathrm{B}$ & 32 & $74.17 \pm 1.94$ & $90.8 \pm 3.3$ & $45.59 \pm 0.58$ & $6.16 \pm 0.07$ \\
\hline & & PS & 32 & $71.76 \pm 0.35$ & $88.3 \pm 0.8$ & $20.71 \pm 0.51$ & $2.80 \pm 0.07$ \\
\hline & & B & 32 & nd & $90.8 \pm 1.7$ & nd & nd \\
\hline & & Unfed & 32 & nd & $74.2 \pm 4.2$ & nd & nd \\
\hline \multirow[t]{4}{*}{3 USA (120) } & \multirow[t]{4}{*}{$91.16 \pm 0.76$} & $\mathrm{PS}+\mathrm{B}$ & 32 & $137.90 \pm 1.02$ & $88.3 \pm 2.5$ & $29.36 \pm 1.90$ & $2.56 \pm 0.10$ \\
\hline & & PS & 32 & $94.27 \pm 0.84$ & $87.5 \pm 1.7$ & $14.15 \pm 0.35$ & $1.55 \pm 0.03$ \\
\hline & & B & 32 & nd & $87.5 \pm 1.7$ & nd & nd \\
\hline & & Unfed & 32 & nd & $70.8 \pm 5.0$ & nd & nd \\
\hline \multirow[t]{4}{*}{4 USA (120) } & \multirow[t]{4}{*}{$46.34 \pm 0.89$} & $\mathrm{PS}+\mathrm{B}$ & 32 & $48.14 \pm 0.91$ & $90.8 \pm 2.5$ & $19.24 \pm 1.17$ & $4.15 \pm 0.25$ \\
\hline & & PS & 32 & $47.88 \pm 0.79$ & $90.8 \pm 1.7$ & $8.46 \pm 0.14$ & $1.83 \pm 0.03$ \\
\hline & & B & 32 & nd & $89.2 \pm 0.8$ & nd & nd \\
\hline & & Unfed & 32 & nd & $75.8 \pm 2.5$ & nd & nd \\
\hline \multirow[t]{4}{*}{5 USA (120) } & \multirow[t]{4}{*}{$84.09 \pm 1.27$} & $\mathrm{PS}+\mathrm{B}$ & 32 & $86.18 \pm 2.16$ & $84.2 \pm 1.7$ & $35.97 \pm 0.05$ & $4.28 \pm 0.01$ \\
\hline & & PS & 32 & $82.18 \pm 1.01$ & $82.5 \pm 1.7$ & $16.46 \pm 0.28$ & $1.96 \pm 0.33$ \\
\hline & & $\mathrm{B}$ & 32 & nd & $85.0 \pm 2.5$ & nd & nd \\
\hline & & Unfed & 32 & nd & $69.2 \pm 3.3$ & nd & nd \\
\hline \multirow{6}{*}{$\begin{array}{l}6 \text { Northern Ireland } \\
(200)\end{array}$} & \multirow[t]{6}{*}{$33.54 \pm 0.59$} & $\mathrm{PS}+\mathrm{B}$ & 35 & $40.98 \pm 0.06$ & $98.0 \pm 0.0$ & $25.82 \pm 0.17$ & $7.64 \pm 0.05$ \\
\hline & & PS & 35 & $35.99 \pm 2.90$ & $95.5 \pm 1.0$ & $19.21 \pm 0.21$ & $5.92 \pm 0.06$ \\
\hline & & Unfed & 35 & $30.80 \pm 1.07$ & $89.0 \pm 2.0$ & nd & nd \\
\hline & & $P S+B$ & 98 & $49.09 \pm 1.84$ & $81.5 \pm 7.1$ & nd & nd \\
\hline & & PS & 98 & $51.60 \pm 15.92$ & $11.5 \pm 4.9$ & nd & nd \\
\hline & & Unfed & 98 & $52.28 \pm 3.54$ & $11.8 \pm 1.1$ & nd & nd \\
\hline
\end{tabular}




\begin{tabular}{|c|c|c|c|c|c|c|c|}
\hline \multirow{2}{*}{$\begin{array}{l}\text { Mealworm source } \\
\text { (no. mealworms) }\end{array}$} & \multirow{2}{*}{$\begin{array}{c}\text { Initial wt mg } \\
\text { worm }^{-1}\end{array}$} & \multirow[t]{2}{*}{ Feed } & \multirow{2}{*}{$\begin{array}{c}\text { Final } \\
\text { day }\end{array}$} & \multirow{2}{*}{$\begin{array}{l}\text { Final wt mg } \\
\text { worm }^{-1}\end{array}$} & \multirow{2}{*}{$\begin{array}{c}\text { Survival } \\
\text { rate } \%\end{array}$} & \multicolumn{2}{|c|}{ Specific PS consumption rate } \\
\hline & & & & & & $\begin{array}{l}\text { mg PS } 100 \\
\text { worms }^{-1} \mathbf{d}^{-1}\end{array}$ & $\begin{array}{c}\text { mg PS g } \\
\text { worms }^{-1} \mathbf{d}^{-1}\end{array}$ \\
\hline 7 China (500) & 63.25 & $\mathrm{PS}+\mathrm{B}$ & 24 & 117.84 & 92.7 & 45.32 & 7.17 \\
\hline 8 China (500) & 76.03 & $\mathrm{PS}+\mathrm{B}$ & 24 & 104.39 & 89.2 & 31.34 & 4.12 \\
\hline 9 China (500) & 80.23 & $\mathrm{PS}+\mathrm{B}$ & 24 & 132.74 & 92.3 & 24.39 & 3.04 \\
\hline 10 China (500) & 61.04 & $\mathrm{PS}+\mathrm{B}$ & 24 & 111.97 & 90.5 & 29.45 & 4.90 \\
\hline 11 China (500) & 85.05 & $\mathrm{PS}+\mathrm{B}$ & 24 & 125.13 & 95.3 & 41.24 & 4.85 \\
\hline 12 China (500) & 51.95 & $\mathrm{PS}+\mathrm{B}$ & 24 & 62.92 & 92.8 & 20.36 & 3.92 \\
\hline
\end{tabular}

a

Specific PS consumption rates were computed as the mass of PS consumed over the test period (32 days for USA sources, 35 days for the UK source, and 24 days for Chinese sources) divided by the initial number of mealworms (column 7) or by the average initial weight of mealworms (column 8). $\mathrm{PS}=$ polystyrene; $\mathrm{B}=$ bran; $\mathrm{nd}=$ not determined.

\subsection{PS feedstocks}

Mealworms received one of three PS feedstocks, labeled A, B, or C. These feedstocks had similar density $\left(0.020-0.021 \mathrm{~g} \mathrm{~cm}^{-3}\right)$ and similar molecular weights (Table S1, Supplementary data). Average molecular weights of the feedstock materials were determined in the analytical laboratories of the Department of Chemistry, Stanford University. Feedstock A consisted of Styrofoam plates from Insulfoam (Carlisle Construction Materials, Puyallup, WA), the number-average molecular weight $\left(M_{n}\right)$ was $90,000 \pm 2,000$, and the weightaveraged molecular weight $\left(\mathrm{M}_{\mathrm{w}}\right)$ was $228,000 \pm 1000$. Feedstock B consisted of white EPS70 SDN insulation Styrofoam from UK Packaging Suppliers (Staffordshire, UK), with $M_{n}$ of $89,000 \pm 2,000$, and $M_{w}$ of $210,000 \pm 2000$. Feedstock $C$ consisted of Styrofoam packing material from Shenzhen, China, with $M_{n}$ of $93,000 \pm 3,000$, and $M_{w}$ of 254,000 \pm 1000 .

2.4. PS biodegradation capability

Mealworms in developmental stages instar 5-7 were cultivated in food grade high density polypropylene (PP) storage containers in laboratories at Stanford, CA, USA; Beijing, China; and Belfast, UK. The set up and methods used were similar to those previously reported (Yang et al., 2018). At Stanford, 120 mealworms were incubated in $475 \mathrm{~mL}$ PP containers; in Northern Ireland 200 mealworms were incubated in $600 \mathrm{~mL}$ containers; in China, 500 mealworms were incubated in $1200 \mathrm{~mL}$ containers. In each incubator, the spatial density of the mealworms was $\sim 2$ worms $\mathrm{cm}^{-2}$. The humidity within the containers was maintained at $75-80 \%$. Temperature was maintained at $25^{\circ} \mathrm{C}$ at Stanford, $24-26^{\circ} \mathrm{C}$ in Belfast, and $26-27^{\circ} \mathrm{C}$ in Beijing. Mealworms from US sources 1-5 and Chinese sources 7- 
11 received Feedstock A; mealworms from the UK source 6 received Feedstock B; mealworms from Chinese source 12 received feedstock $C$. All tests in the USA and UK were performed in duplicate. An additional test was performed at Tongji University: mealworms from source 11 (Shanghai) were tested for survival under different feeding conditions at ambient temperature $\left(25-26^{\circ} \mathrm{C}\right)$ over a 34-day test period.

At Stanford, mealworms were fed PS alone and PS plus bran. To initiate these tests, $1.80 \mathrm{~g}$ PS feedstock was added to each incubator. For the PS alone diet, no additional PS was added thereafter. For the PS plus bran diet, each incubator received $3.6 \mathrm{~g}$ bran supplements every 4 days, resulting in a cumulative bran to PS ratio (B/PS) of 14:1 over a 32-day period (Yang et al., 2018). In Belfast, all incubators initially received PS (1.0 g). For the PS alone diet, no additional PS was added thereafter. For the PS plus bran diet, bran supplements $(1.0 \mathrm{~g})$ were provided weekly. Unfed mealworms were used as control. In Beijing, mealworm incubators were fed PS plus bran. Each incubator initially received $8.3 \mathrm{~g}$ PS plus $14.8 \mathrm{~g}$ bran; this was followed by $14.8 \mathrm{~g}$ bran supplements every 4 days thereafter, resulting in a cumulative $\mathrm{B} / \mathrm{P}$ ratio of 8.9:1 over a 24-day period. In tests at all three labs, dead mealworms were removed whenever observed. Tests conducted at Tongji University were carried out in four incubators initially containing 410 mealworms per incubator. Mealworms were fed one of three diets at the beginning: (1) $8.5 \mathrm{~g}$ bran, (2) $4.70 \mathrm{~g}$ PS, and (3) $4.7 \mathrm{~g}$ PS plus $8.5 \mathrm{~g}$ bran. Bran was supplemented every 5 days with a cumulative B/P ratio of 14.5:1. Unfed controls were also evaluated.

Mealworm survival rates (SRs) and PS mass losses were monitored and calculated. For DNA analyses, mealworms samples (at least 30) were collected, preserved with $100 \%$ ethanol (analytical grade) and stored at $-80{ }^{\circ} \mathrm{C}$.

\subsection{Characterization of feedstock and frass}

Biodegradation and depolymerization of ingested PS was assessed by GPC and FTIR analyses of feedstock and frass. Frass from each incubator was collected and extracted as described in the Supplementary data and a previous report (Yang et al., 2018). The respective feedstock PS materials were extracted using the same procedures as frass samples prior to GPC analysis. Triplicate GPC analyses were carried out at Stanford University to determine $\mathrm{M}_{\mathrm{n}}, \mathrm{M}_{\mathrm{w}}$ and molecular weight distribution (MWD) of feedstock and frass samples. Triplicate $100-\mu \mathrm{L}$ frass extract samples were injected into a GPC operating at a THF eluent flow rate of $1.0 \mathrm{~mL} \mathrm{~min}^{-1}$ at $40^{\circ} \mathrm{C}$ (Viscotek GPCmax VE 2001 GPC Solvent/Sample Module, Viscotek Corporation, Houston, Texas, USA). Triplicate FTIR analyses (EQUINOX 55 FTIR Spectrometer, Bruker Corporation, Ettlingen, Germany) were performed at Tongji University to characterize functional groups in PS feedstocks and frass samples over the range $400-4000 \mathrm{~cm}^{-1}$. 


\subsection{Effect of antibiotics on PS degradation}

The effect of antibiotic suppression on PS depolymerization and degradation was tested using mealworms from US sources 1-5 and gentamicin as an inhibitor. Gentamicin was selected based on the results of Yang et al. (2015b). Mealworms (120 per container) were fed bran mixed with gentamicin sulfate (Cat\# 00149, Lot\# 001204-15032306, Chem-Impex Int'l Inc., USA) at a dosage of $30 \mathrm{mg}$ gentamicin sulfate per gram of bran. Controls were fed bran alone. On day 0,7 , and 15, 15 mealworms in each incubator were randomly chosen from each source of mealworms to prepare a gut suspension for counting of gut microorganisms. The surfaces of the worms were decontaminated by immersion in 70\% ethanol for $1 \mathrm{~min}$ then rinsing twice with distilled water. The gut contents of 15 mealworms from each source were then extracted and suspended in $5 \mathrm{~mL}$ sterilized saline water $(7.5 \% \mathrm{NaCl})$. This initial gut suspension was diluted using a five-step ten-fold serial dilution $\left(10^{-1}\right.$ to $\left.10^{-5}\right)$ and spread on Trypticase soy agar (TSA) plates containing $15 \mathrm{~g} \mathrm{~L}^{-1}$ tryptone, $5 \mathrm{~g} \mathrm{~L}^{-1}$ soytone, $5 \mathrm{~g} \mathrm{~L}^{-1}$ sodium chloride, $15 \mathrm{~g} \mathrm{~L}^{-1}$ agar, $\mathrm{pH} 7.3 \pm 0.2$, a general-purpose, nonselective medium providing enough nutrients to allow for a growth of a wide variety of microorganisms. After incubation for $24 \mathrm{~h}\left(\right.$ at $\left.30^{\circ} \mathrm{C}\right)$, the number of colonies were counted. On day 7 , mealworms from the antibiotic treatment and the control treatment were fed PS feedstock. Gentamicin sulfate mixed bran ( $30 \mathrm{mg}$ gentamicin sulfate $\mathrm{g} \mathrm{bran}^{-1}$ ) was then continuously supplied to the treatment group until day 15. Over the 15-day incubation period, frass samples from both treatment and control incubations were collected for GPC analysis.

2.7. Gut microbial community analysis

Mealworm samples from each strain were collected, preserved in $100 \%$ ethanol at $-80{ }^{\circ} \mathrm{C}$, and shipped to the lab for microbial community analysis. DNA extraction from externally decontaminated larval mealworms was performed using the DNeasy Blood and Tissue kit (Qiagen) before library construction and sequencing $(2 \times 250$ bp paired-end reads, Illumina MiSeq) were performed at the Michigan State University Genomics Core Facility. Sequencing reads were filtered and taxonomically assigned using QIIME 2. Additional methods are available in the supplemental materials.

\section{Results and discussion}

\subsection{Ubiquity of plastic eating behavior among mealworms}

Survey responses from collaborators in 22 countries (Fig. 1) indicated that mealworms in all locations consumed PS foam, including mealworms from North America (Canada, Mexico, USA); Asia (Cambodia, China, Japan, Indonesia, Iran, Israel, South Korea, Thailand); Europe (Finland, France, Germany, Poland, Slovenia, Spain, Turkey, UK); Africa (Nigeria, South Africa) and Australia. From these results, we surmise that chewing and ingestion of PS is 
likely an adaptive behavior intrinsic to yellow mealworms, which feed upon decaying forest vegetation in natural settings (Howard, 1955). Marshall School students (Duluth MN, USA) reported $33 \mathrm{mg}$ PS 100 worms $^{-1} \mathrm{~d}^{-1}$, within the range of previous tests; a team at the University of Queensland, St. Lucia, Australia, reported that local mealworms consumed PS at a rate of $13 \mathrm{mg}$ PS 100 worms $^{-1} \mathrm{~d}^{-1}$; a team in Bandar Lampung, Indonesia, reported that PS foam feeds supported mealworm growth, and the feed had no significant effect on larvaemortality (Nukmal et al., 2018); and students reported formation of beetles from larvae when fed PS plus bran, confirming prior reports (Yang et al., 2015a, Yang et al., 2018). Mealworms were also observed consuming PE, an observation now documented in the peer-reviewed literature (Brandon et al., 2018), as well as other plastics, including PVC and PLA, as reported by an academic team in Poland (Boźek et al., 2017).

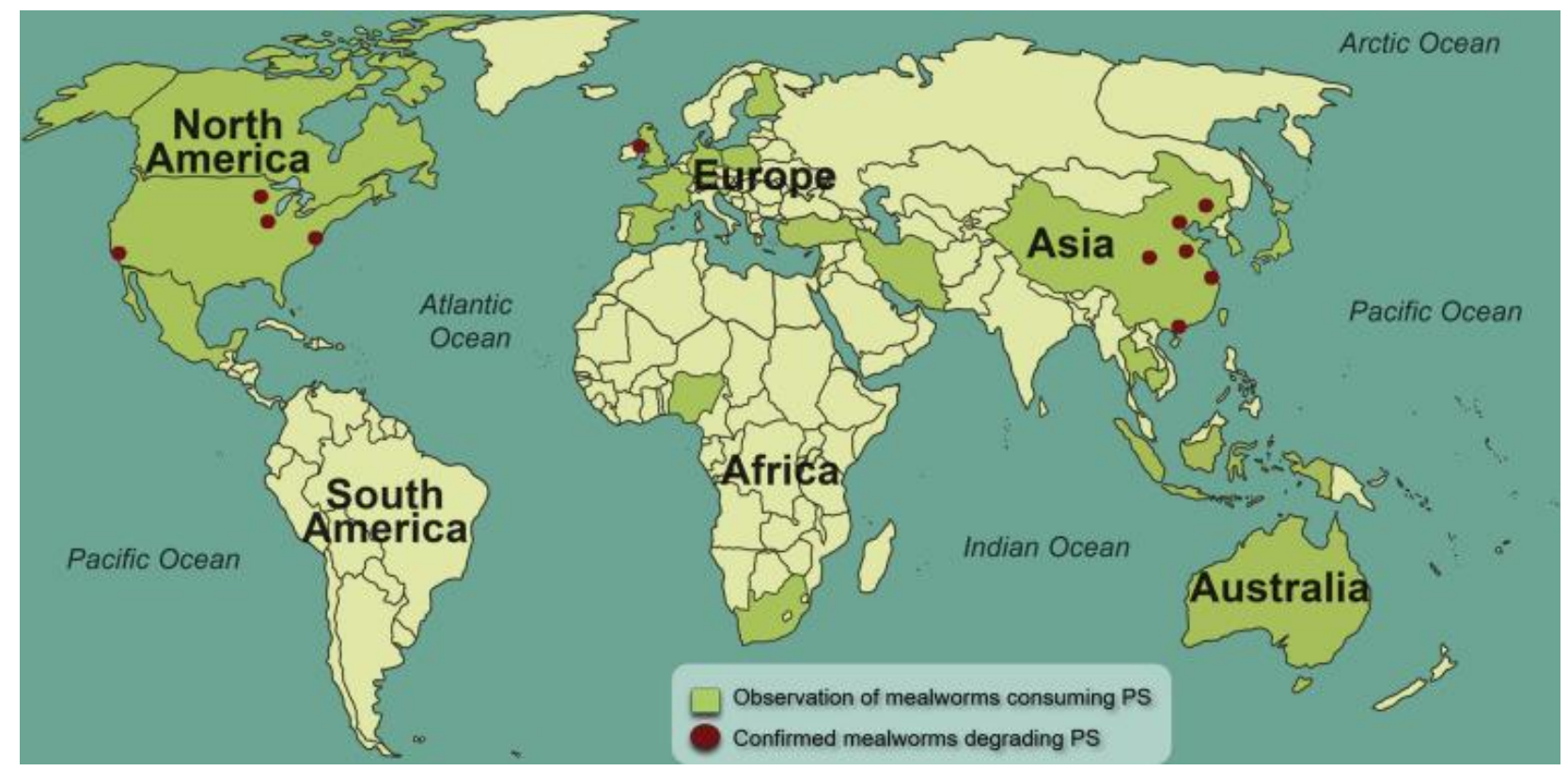

Fig. 1. Locations where mealworm consumption of plastic has been observed (green) and where mealworms have been tested in biodegradation studies (red dots). The figure was adapted from www.paonazario.com. (For interpretation of the references to color in this figure legend, the reader is referred to the Web version of this article.)

\subsection{Ubiquity of biodegradation of PS}

The ubiquity of PS biodegradation was evaluated by testing mealworms from twelve distinct geographic locations with three PS feedstocks (Table 1). All mealworms chewed and ingested PS (Fig. 2). For mealworms from sources 1-6, 32-day survival rates (SRs) for mealworms fed PS alone exceeded $80 \%$ (Table 1). These values were statistically indistinguishable from the 32-day SRs of mealworms fed PS plus bran (Table 1). 

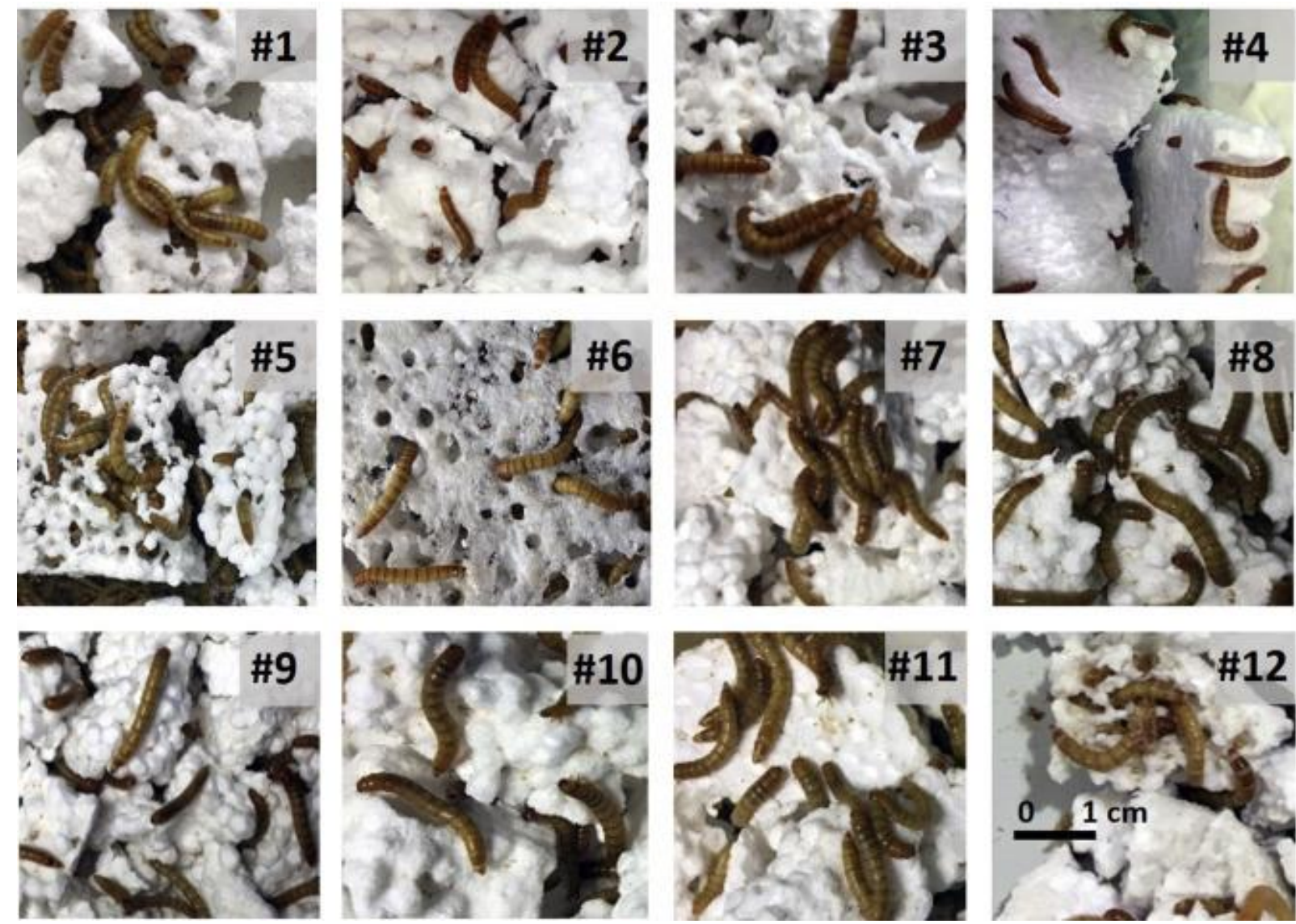

Fig. 2. Plastic feeding behavior of mealworms used for PS biodegradation tests. Sources 1 to 5 are from the USA, source 6 is from the UK, and sources 7-12 are from China. See also Table 1.

Over a 32-day period, SRs for mealworms from US sources 2 through 5 were higher for mealworms fed bran only (88-90\%), PS plus bran (85-92\%), and PS only (83-92\%) than for unfed mealworms (69-76\%) (Table 1 and Fig. S2, Table S1). Higher SRs were also observed in mealworms from source 11 (Shanghai) when fed PS plus bran (95\%) or PS only (92\%) compared to unfed mealworms (68\%) over a 34-day period (Fig. S1C, Table S2).

The average weight of mealworms from source 6 (Northern Ireland) increased by $22 \%$ over a 34-day period when fed bran or PS plus bran, but only increased by $7.3 \%$ when fed PS alone, and decreased by $8.2 \%$ when unfed (Table 1). Similarly, the average weight of mealworms from source 11 (Shanghai) increased by 16-25\% over a 34-day period for mealworms fed bran or PS plus bran, but decreased by $9.3 \%$ when fed PS alone and by $17.4 \%$ when unfed (Table S2, Supplementary data).

These results indicate that digestion of ingested PS can provide significant energy (source 6) and offset energy requirements for maintenance for over one month (source 11). In a previous test of the Beijing strain fed $\alpha{ }^{13} \mathrm{C}$ - and $\beta{ }^{13} \mathrm{C}$-labeled PS (Yang et al., 2015a), individual fatty acids had $\delta{ }^{13} \mathrm{C}$ values that were significantly higher than bran-fed controls, especially in unsaturated FAs, indicating that ${ }^{13} \mathrm{C}$ from the ${ }^{13} \mathrm{C}$-labeled PS was assimilated into mealworm biomass. This is evidence that PS digestion can provide both energy and carbon for 
mealworm maintenance and survival during the first month of cultivation (Yang et al., 2015a, Yang et al., 2018). Further studies are needed to understand the conditions regulating the mechanisms of energy recovery from plastic consumption. Whether the mealworms obtain sufficient energy for maintenance likely depends upon the PS consumption rate and digestibility of the PS consumed.

In the 98-day tests of mealworms from source 6, the SRs of mealworms fed PS alone matched those fed PS plus bran during the initial 35 days of incubation (95.5\% versus $98.0 \%)$ then dropped to low levels, like those of unfed controls (Table 1). Further investigation revealed that both the unfed mealworms and mealworms fed PS alone engaged in cannibalism. The 98-day SR was $11.8 \pm 1.1 \%$ for unfed mealworms, and $11.5 \pm 4.9 \%$ for mealworms fed PS alone. By contrast, the 98-day SR for mealworms fed bran plus PS was $81.5 \pm 7.1 \%$ (Fig. S1B). Because PS contains only hydrogen and carbon, it does not provide adequate nutrition ( $\mathrm{N}, \mathrm{P}, \mathrm{Na}, \mathrm{K}$, trace elements, amino acids, etc.) for a long-term survival and growth. The positive effect of PS on SR does not last for long time due to the lack of nitrogen sources and other nutrients. The addition of bran relieved this constraint. In the absence of added bran, however, PS-fed mealworms survived by consuming dead mealworms and their molts. The survivors (about $12 \%$ of the original population) maintained a biomass similar to those that received bran (Table 1).

Specific PS consumption rates from US sources 1-6 and Northern Ireland UK source 7 were compared for mealworms fed PS alone and bran plus PS (Table 1). Mealworms fed bran plus PS typically consumed PS at rates that were more than twice those of mealworms fed PS alone. Not surprisingly, mealworms from sources 1 and 2 (same source, but different batch) had similar PS specific consumption rates. The initial size of the mealworms had no clear impact on the rate of PS consumption, but the lightest mealworms (source 6; average weight $33.5 \mathrm{mg}$ ) consumed PS at the highest rate (7.64 $\mathrm{mg}$ PS g worms $\left.{ }^{-1} \mathrm{~d}^{-1}\right)$.

For the mealworms obtained in China, PS consumption rates were evaluated under relatively optimal conditions. While the results varied, the ranges observed were similar to those of mealworms from the USA and North Ireland (Table 1).

\subsection{Characterizations of the egested frass}

During incubation with PS as a feedstock, decreases in $\mathrm{M}_{n}$ and $\mathrm{M}_{\mathrm{w}}$ and MWD shifts to were monitored (Albertsson et al., 1998; Yang et al., 2015a, Yang et al., 2018). Fig. 3 shows evidence of PS depolymerization within the guts of mealworms from all 12 sources, with significant decreases in $\mathrm{M}_{\mathrm{n}}$ and $\mathrm{M}_{\mathrm{w}}$ accompanied by shifts in MWD to lower molecular weights ( $t$-test $\mathrm{p}<0.05$ in Table S2). 

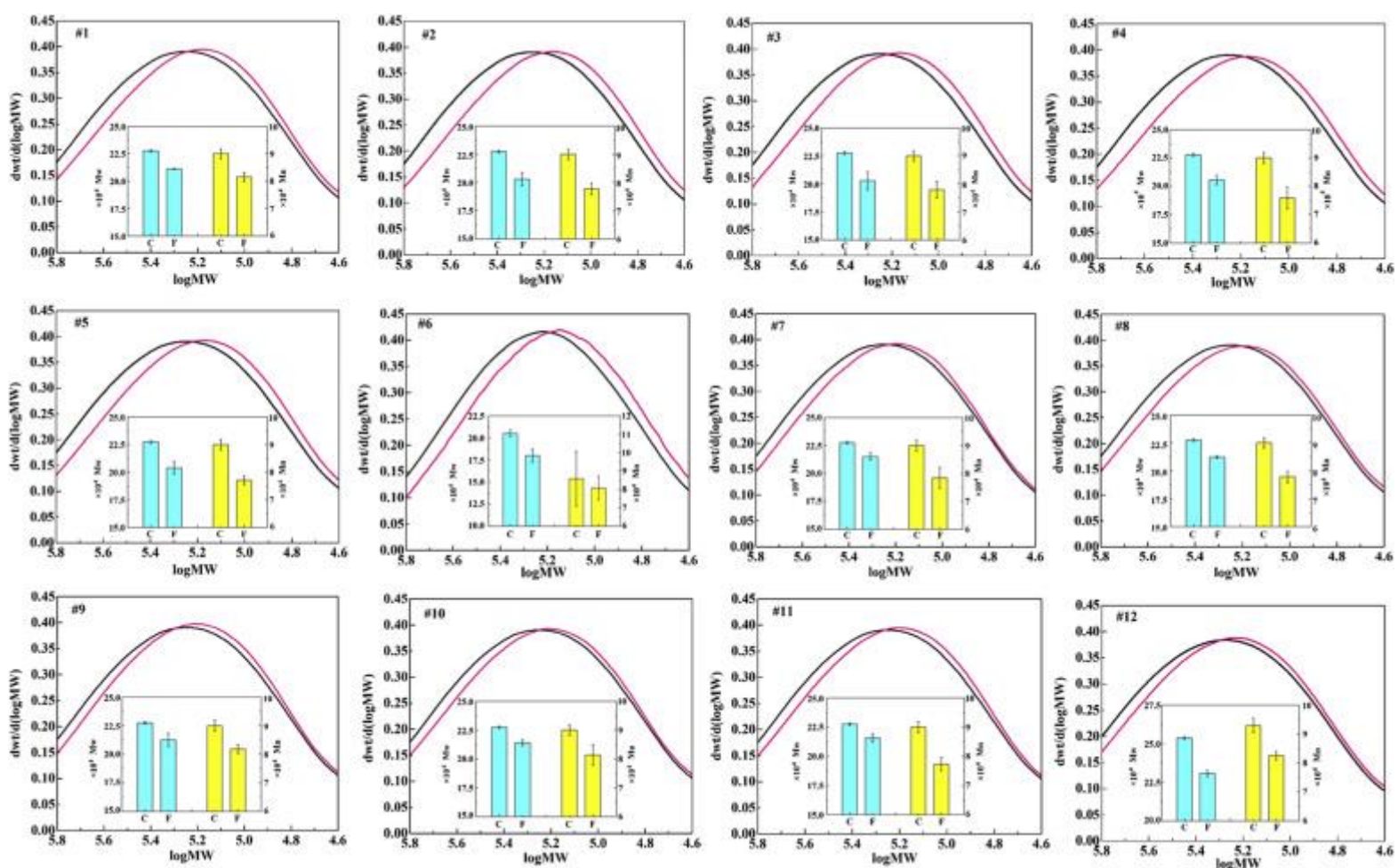

Fig. 3. Changes in molecular weights $M_{w}$ (blue) and $M_{n}$ (yellow) and in molecular weight distribution (MWD) of PS feedstock (black curves) and PS polymer residues extracted from frass samples (red curves) for mealworms from each of the 12 sources. Panels 15 summarize data for sources in the USA; Panel 6 illustrates data for Northern Ireland; and Panels 7-12 summarize data for Chinese sources. (For interpretation of the references to color in this figure legend, the reader is referred to the Web version of this article.)

Frass samples from mealworms from US sources 1-5 and Chinese sources 7-11 contained polymer extracts with $\mathrm{M}_{\mathrm{n}}$ values that were 9.1-15.6\% lower than the feedstock and had $\mathrm{M}_{\mathrm{w}}$ values that were 5.2-10.8\% lower than the feedstock (Feedstock A with $\mathrm{M}_{\mathrm{n}}$ of $90,000 \pm 2000 ; M_{w}$ of 228,000 \pm 1000 ) (Table S3, Supplementary data). Frass samples from mealworms from Northern Ireland (source 6) had $M_{n}$ values that were 5.4\% lower and $M_{w}$ values that were $12.1 \%$ lower than the feed (Feedstock B with $M_{n}$ of 89,000 $\pm 2000 ; M_{w}$ of $210,000 \pm 2000$ ). For frass samples from Chinese source $12, M_{n}$ values were $11.2 \%$ lower, and $M_{w}$ values were $9.0 \%$ lower than the feed (Feedstock $C$ with $M_{n}$ of 93,000 \pm 3000 and $M_{w}$ of 254,000 1000 (Table S3). These decreases in $M_{n}$ and $M_{w}$ were significant for all sources ( $t$-test, $\mathrm{p}<0.05$, Table S2), indicating depolymerization and degradation of PS feedstock was ubiquitous across all 12 source populations.

FTIR analyses verified the formation of new functional groups during passage through the mealworm gut. Comparison of FTIR spectra for the PS feed stock (control) and egested frass of all tested mealworms showed chemical changes and incorporation of oxygen previously linked to plastic degradation (Fig. 4 A and 4B, Fig. S3 and S4, Supplementary data). These data are similar to those previously reported (Yang et al., 2018; Brandon et al., 2018). The spectra of frass from mealworms fed with PS and PS plus bran are significantly different 
from the frass of mealworms fed bran only (Fig. 4A and Fig. S3, Supplementary data). Peaks at $625-970 \mathrm{~cm}^{-1}$ (ring-bending vibration) had high intensities in the PS feedstock but were much weaker in frass samples. Peaks characteristic of the PS benzenering $(\mathrm{C}=\mathrm{C}$ stretch, 1550-1610 and 1800-2000 $\mathrm{cm}^{-1}$ ) were dampened in frass of mealworms fed PS or PS plus bran, suggesting ring cleavage. The PS fed samples showed a decrease intensity for peaks characteristic of PS (Sekhar et al., 2016) and appearance of more carbonyl groups $(\mathrm{C}=\mathrm{O}$ stretching, $1700 \mathrm{~cm}^{-1}$ ) compared with samples fed bran alone or PS feedstock (Fig. 4A and B, Fig. S3, Supplementary data). The broadening of peaks at $2500-3500 \mathrm{~cm}^{-1}$ in all FTIR spectra is associated with the hydrogen bond of hydroxyl groups and/or carboxylic acid groups, suggesting a shift from hydrophobic to more hydrophilic surface properties. FTIR analysis confirmed that all frass samples showed strong signs of PS biodegradation, as observed in previous tests of mealworms from Beijing (Yang et al., 2015a) and a California PetCo store (Yang et al., 2018).
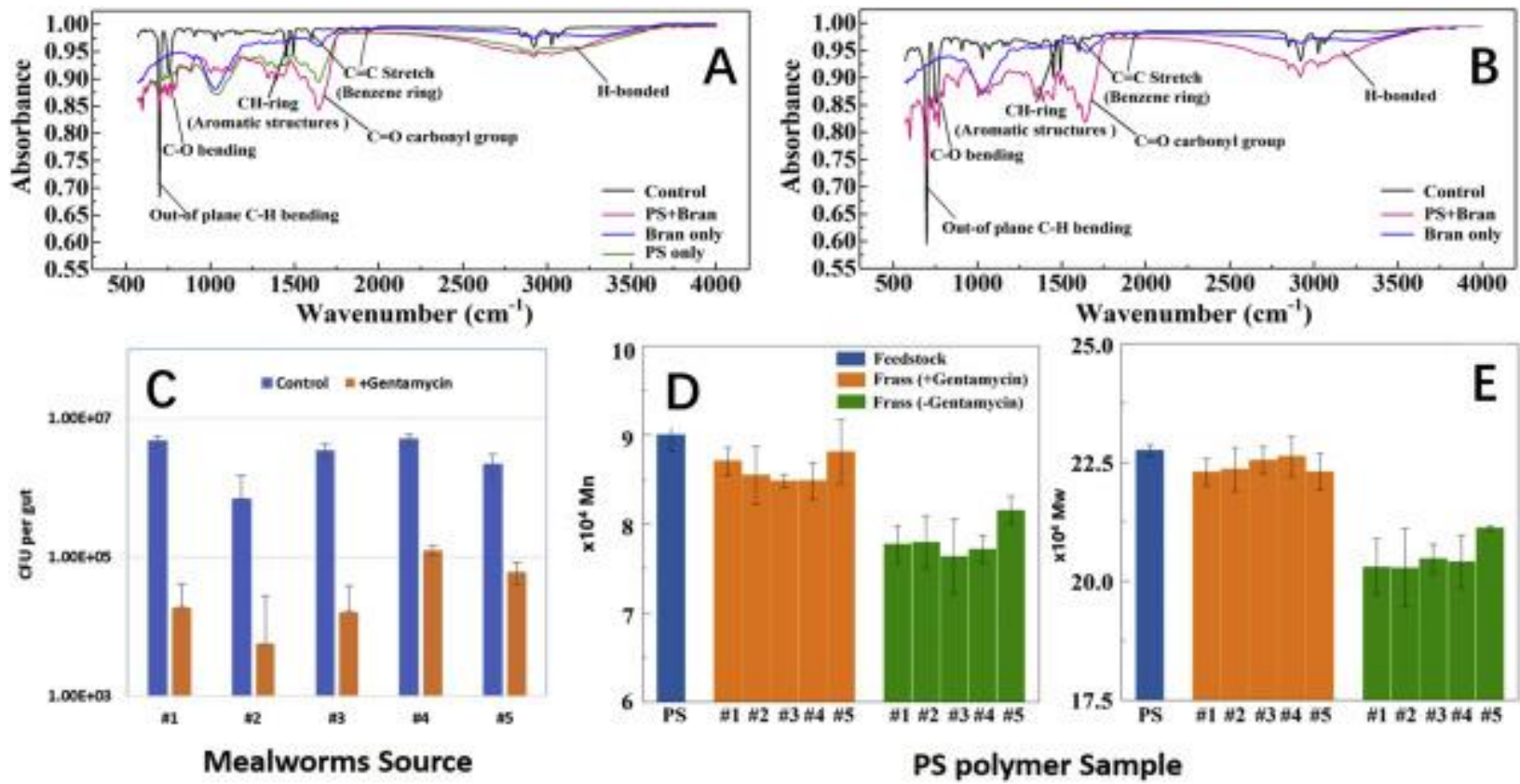

Fig. 4. Formation of functional intermediate groups of PS degradation and the effect of gentamicin inhibition on Styrofoam depolymerization. Panel A shows FTIR spectra of PS feedstock (Control), and frass of mealworms (Source 1) fed with PS only, PS plus bran, and bran only. Panel B shows FTIR spectra of frass of mealworms (Source 2) fed with PS plus bran, and bran only. Panel $\mathbf{C}$ shows the decrease in gut bacterial counts within mealworms after feeding of gentamycin over a 7 day period. Panel $\mathbf{C}$ shows $\mathbf{M}_{n}$ and Panel $\mathbf{D}$ shows $\mathrm{M}_{\mathrm{w}}$ for the PS feedstock (blue) compared to values for the frass from mealworms receiving gentamycin (orange) and without gentamycin (green) from USA sources 1-5. (For interpretation of the references to color in this figure legend, the reader is referred to the Web version of this article.) 


\subsection{Effect of gentamicin on PS depolymerization}

Antibiotics, such as nystatin and ampicillin, suppress gut microbiota in mealworms and provide insight into the role that gut microbiota play in digestive processes, such as the digestion of cell walls and glucoside detoxification (Genta et al., 2006). Previous studies have inferred that gut microbes were required for PS biodegradation due to suppression of PS degradation when gentamycin was added (Yang et al., 2015b). Gentamicin addition to the diets of mealworms from the five USA sources was used to examine the role of gut bacteria on PS depolymerization/biodegradation. After feeding gentamicin sulfate plus bran for 7 days, gut bacteria numbers dropped significantly from $10^{6}$ levels by $2-3$ magnitudes compared to controls (Fig. 4C and Table S5), indicating suppression of the gut bacteria. After 15 days, frass samples were collected for tetrahydrofuran (THF) extraction and GPC analysis of residual polymers. GPC analyses indicated inhibition of depolymerization when the mealworms were fed gentamicin-containing bran, but depolymerization remained elevated in the control treatment (Fig. 4D and E). No statistically significant differences were observed in $M_{w}$ and $M_{n}$ values between PS feed stock and residual polymers extracted from frass samples of mealworms receiving the gentamicin treatment for all five US sources (Table S6). On the other hand, significant differences were observed in $M_{w}$ and $M_{n}$ values between PS fed stock and residual polymers extracted from control and gentamicin treatments (Tables S6 and S7). This is evidence that gentamycin suppressed gut microbiota and inhibited PS depolymerization. From these results, we hypothesize that the depolymerization of PS may be induced by gut microbes that are directly in contact with PS or entail synergetic effects involving gut microflora and mealworm digestive enzymes within the gut. Our results showed that unfed mealworms showed slight but reproducibly lower SR. It seems that microbes in the gut of mealworms cause a partial depolymerization of PS with the release of broken down substances which sustain the SR of mealworms even in the absence of other food (such as bran). Further study is needed to examine wether antibiotics causes lower SR for mealworms fed PS only.

\subsection{Gut microbial community analyses}

The dominant bacterial phyla across all mealworm samples, representing greater than $99 \%$ average relative abundance in the measured bacterial communities, were Actinobacteria, Firmicutes, Proteobacteria and Tenericutes. The six most abundant families ( $>98 \%$ total relative abundance on average)

were Bacillaceae, Enterobacteriaceae, Enterococcaceae, Lactobacillaceae, Leuconostocacea $e$, and Streptococcaceae representing a diverse range of mostly aerobic and/or facultative bacteria. Fig. 5 illustrates differences in bacterial taxa between mealworms fed normal feed bran (Original) and mealworms fed PS alone and PS plus bran (PS/Bran). The original bacterial communities varied greatly between source populations, likely due to differences in 
diet at different geographic locations and strain-specific properties (genes, growth condition and history). However, after mealworms switched diets from bran to PS plus bran or to PS alone, the gut microbial communities converged on similar patterns independent of the mealworm source.
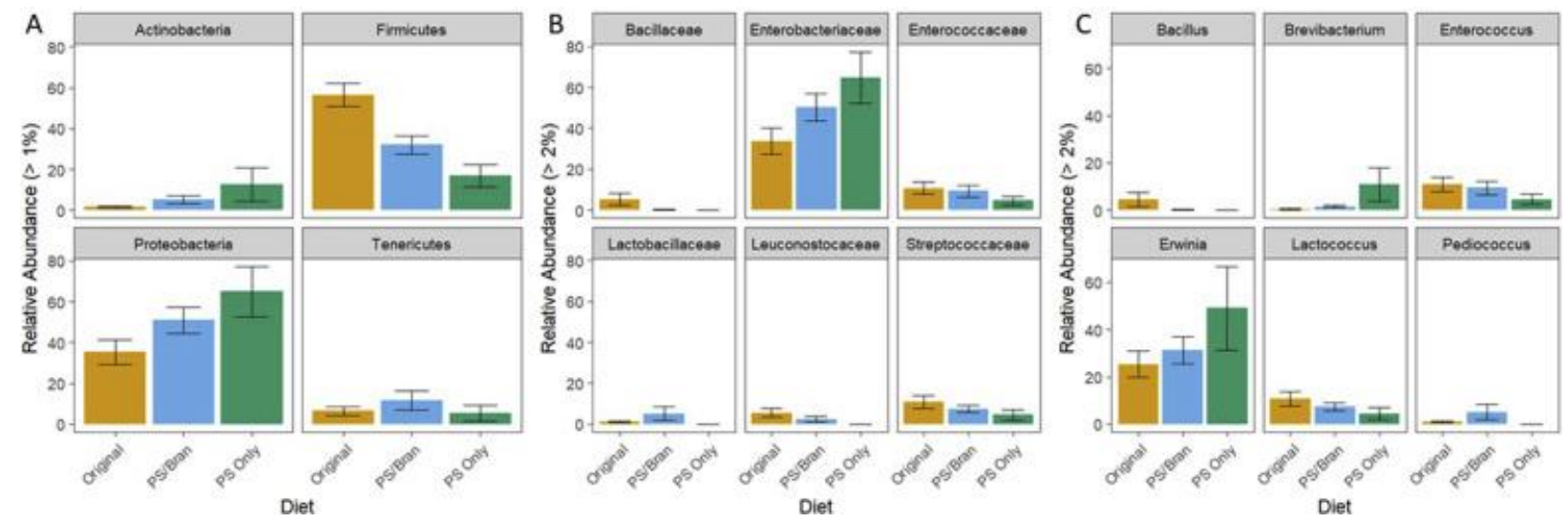

Fig. 5. Relative abundances of dominant (A) phyla, (B) families, and (C) genera in internal microbial communities from original mealworms (orange) versus those fed with PS (gold) and bran plus PS (purple). Error bars indicate standard deviations for multiple mealworm samples. Taxa with a relative abundance less than the threshold stated in each figure label are not shown. Significance is shown with lowercase letters; all other comparisons were not significantly different after adjusting for multiple comparisons. (For interpretation of the references to color in this figure legend, the reader is referred to the Web version of this article.)

At the phylum level, the relative abundance of Firmicutes decreased significantly in the PSonly diets $(\mathrm{P}=0.0055)$ and the PS plus bran diet (Wilcox, $\mathrm{P}=0.0035)$. There were no significant differences between the PS-only diet and the PS plus bran diet $(\mathrm{P}=0.293)$. Firmicutes include Clostridia (anaerobic bacteria) and Bacilli (aerobic bacteria), and both are spore formers. No other phyla were significantly different between treatments though Proteobacteria abundance showed an inverse relationship with Firmicutes (Fig. 5A). At the family level, Enterobacteriaceae represented $33.7 \%(\mathrm{SE} \pm 6.3 \%)$ of total relative abundance in the original diet, $64.6 \pm 12.5 \%$ in the PS-only diet, and $50.2 \pm 6.5 \%$ in the PS plus bran diet (Fig. 5B). After adjusting $\mathrm{P}$ values for multiple comparisons, there were no significant differences in relative abundance of any family. At the genus level, Erwinia was the most prevalent genus, representing $25.3 \pm 5.65 \%$ in the original treatment, $49.1 \pm 17.6 \%$ in the PSonly treatment, and $31.2 \pm 5.64 \%$ in the PS plus bran treatment, with no significant differences between diets (Fig. 5C).

When the diet of the mealworms shifted from bran to PS-only or PS plus bran, the gut microbiota shifted to a community with improved capabilities for PS degradation. At present, however, it is difficult to prove which microbial genera or families are responsible for enhanced PS degradation because only a few PS-degrading bacteria have been isolated. 
These include PS-degrading Exiguobacterium sp. YT2 (Yang et al., 2015b), Phylum: Firmicutes; Class Bacilli, and Rhodococcus ruber (Mor and Siva, 2008), Phylum Actinobacteria, Family Nocardiaceae. Recently, Tang et al. (2017) reported two bacterial strains isolated from the guts of mealworms and superworms' that are capable of growing on PS - Aeromonas sp and Klebsiella pneumoniae - both of which belong to the family Enterobacteriaceae (P Proteobacteria, C Gammaproteobacteria). It is reasonable to hypothesize that PS-degrading bacteria are able to secrete extracellular oxidative enzyme(s) that break down PS polymer chains and generate intermediates with $\mathrm{C}=\mathrm{O}$ bonds; features present in broad families of aerobic or facultative bacteria. Additional isolation and characterization of PS-degrading species is needed to enable identification of key functional enzymes involved in the depolymerization and biodegradation of PS, PE and other plastics. Given the shifts in taxonomic composition that occurred after the mealworms were fed a diet containing PS, this work suggests that bacteria responsible for depolymerizing PS and degradation of intermediates likely include Gram-positive Clostridia (anaerobic conditions), Gram-negative Enterobacteriaceaea (anaerobic-aerobic conditions) and Gram-positive Bacillus (aerobic conditions).

The results of this study indicate that microbiomes capable of depolymerizing PS are widely present in mealworm gut from various sources and that shifts in gut microbial communities may be a direct result of PS consumption (i.e. a changing community to better degrade plastics) or an indirect response (i.e. a response to nutrient deprivation due to the limited diet). We did not evaluate changes in the gut microbial community under starvation conditions and additional studies of such conditions are warranted.

\subsection{Significance of the ubiquity of PS degradation by mealworms}

The results of the global survey strongly suggest that mealworm ingestion of plastic foams, like Styrofoam, is genetically-programmed and ubiquitous. Rapid PS depolymerization was observed, as observed previously (Yang et al., 2015a, Yang et al., 2018), and this capability is apparently conserved in mealworm populations throughout the world. These mealworm populations ingest and use PS foam as a food (energy) source for survival, and this behavior is not limited to PS: PE can be consumed even more rapidly than PS. Approximately $49.0 \pm 1.4 \%$ of ingested PE was converted into a putative gas fraction (i.e. $\left.\mathrm{CO}_{2}\right)($ Brandon et al., 2018). Evidence of mealworm consumption is now available for many other materials, including PP, PVC, PET and PUR at laboratories in the USA and China (data not shown). Other academic researchers have reported mealworm consumption of PVC and PLA (Boźek et al., 2017).

Chewing of plastic into small fragments increases the surface area of the ingested plastic and thus likely enhances enzymatic depolymerization, but depolymerization of the ingested plastic was not completed in the 14-18 h transit time through the mealworm gut. Residual PS 
in the frass contributes to the THF extractable fraction, constituting $~ 35 \%$ of the weight of frass (Yang et al., 2018). Further testing is needed to determine whether this residual is recalcitrant, say, for example, because of crystallinity differences in the PS feedstock, or whether this PS could be degraded with additional residence time in the mealworm gut. In any case, this work establishes that ingestion of PS and PE plastic foam can provide energy for maintenance of mealworm populations for 4-5 weeks. However, a sustained diet of plastic without supplemental nutrition does not enable reproduction of mealworms (Yang et al., 2018) and eventually leads to canabalism.

The ability of insects to depolymerize diverse plastics is likely ubiquitous and not restricted to mealworms. The fact that insect pests, including darkling beetles (Tribolium castaneum, Rhizopertha Lasioderma serricorne, Tnebrioide mauretanicus, Zophobas morio etc. in family Tenebrionidae) and several moths and their larvae (Plodia interpunctella, Galleria mellonellain the Family Pyralidae) can chew, eat, and penetrate various plastic packing materials has been established since the 1950s (Gerhardt and Lindgren, 1954; Cline, 1978; Newton, 1988; Bombelli et al., 2017). These early studies established that insect larvae chew and damage PE, PVC and polyester films regardless of whether the film was used to cover food (Cline, 1978), suggesting that the larvae of insect pests may also ingest plastics as food. Recent studies indicated that the larvae of Plodia interpunctella (Indian meal moth) and Galleria mellonella, or honey waxworms, can chew and likely degrade PE films (Yang et al., 2014; Bombelli et al., 2017).

\section{Conclusions}

This work establishes that mealworms have an intrinsic capacity for biodegradation of PS due to their intrinsic eating and chewing behaviors and gut microbe-dependent oxidative digestive machinery. Digestion of PS contribute to the energy needs of the mealworms. These features appear to be ubiquitous within mealworms from diverse geographic locationsand can be enhanced by co-feeding of nutrient sources such as bran. The contributing gut microbial communities are diverse and subject to dietary control.

\section{Acknowledgments}

This work was supported in part by the Woods Institute for Environment at Stanford University (award 1197667-10-WTAZB) and in part by US National Science Foundation SBIR award 1648559. Dr. Shangshang Yang was supported by the Harbin Institute of Technology, Harbin, China. We also gratefully acknowledge helpful suggestions from Dr. Yu Yang, Beihang University, Beijing, China, and from Drs. Virginia Emery and Hans Kelstrup, Beta Hatch Corp., Seattle, Washington. Finally, we thank Mr. Jack Chiueh, Stanford University, for administrative help and Ms. Andria T. Wu, DePaul University, for figure 
preparation. The authors offer their deepest appreciation and thanks to the many researchers from around the world who contributed to the mealworm survey reported here.

\section{References}

Al-Salem, S.M.; Lettieri, P.; Baeyens, J. Recycling and recovery routes of plastic solid waste (PSW): A review. Waste Manage. 2009, 29 (10), 2625-2643.

Albertsson, A.C.; Erlandsson, B.; Hakkarainen. M.; Karlsson, S. Molecular weight changes and polymeric matrix changes correlated with the formation of degradation products in biodegraded polyethylene. J. Environ. Polym. Degrad. 1998, 6, 187-195.

Bonhomme, S.; Cuer, A.; Delort, A.M.; Lemaire, J; Sancelme, M.; Scott, G. Environmental biodegradation of polyethylene. Polym. Degrad. Stabil. 2003, 81 (3), 441-452.

Boźek, M.; Hanus-Lorenz, B.; Rybak, J. 2017. The studies on waste biodegradation by Tenebrio molitor. E3S Web of Conferences, 2017, 17, 00011.

British Plastic Federation. Plastic waste management. <http://www.bpf.co.uk/ bpfissues/Waste/Management.cfm.>

Brandon, A.M; Gao, S.-H.; Tian, R.; Ning, D.-L.; Yang, S.-S.; Zhou, J.-Z., Wu, W.-M.; Criddle, C.S. Biodegradation of polyethylene in mealworms (larvae of Tenebrio molitor Linneaus): depolymerization, mineralization, and effects on the gut microbiome. Environ. Sci. Technol. 2018, (submitted).

Guillet, J. E.; Regulski, T. W.; McAneney, T. B. Biodegradability of photodegraded polymers II: tracer studies of biooxidation of Ecolyte PS polystyrene. Environ. Sci. Technol. 1974, 8, 923925.

Howard, R.S. The biology of the grain beetle Tenebrio molitor with particular reference to its behavior. Ecology. 1955, 36(2), 262-269.

Kaplan, D.L.; Hartenstein, R.; Sutter, J. Biodegradation of polystyrene, poly(methyl methacrylate), and phenol formaldehyde. Appl. Environ. Microbiol. 1979, 38 (3), 551-553.

Lithner, D.; Larsson, Å.; Dave, G. Environmental and health hazard ranking and assessment of plastic polymers based on chemical composition. Sci. Total Environ. 2011, 409 (18), 3309-3324.

Mor, R., Sivan, A. Biofilm formation and partial biodegradation of polystyrene by the actinomycete Rhodococcus ruber. Biodegradation 2008, 19 (6), 851-858.

Mueller, R.J. Biological degradation of synthetic polyesters-Enzymes as potential catalysts for polyester recycling. Process Biochem. 2006, 41 (10), 2124-2128.

Municipal Solid Waste in the United States: 2007 Facts and Figures. United States Environmental Protection Agency.

Municipal Solid Waste Generation, Recycling, and Disposal in the United States: Facts and Figures for 2012. United States Environmental Protection Agency.

<https://www.epa.gov/sites/production/files/2015-09/documents/2012_msw_dat_tbls.pdf>

Murakata, T.; Saito, Y.; Yoshikawa, T.; Suzuki, T.; Sata, S. Solvent effect on Thermal Degradation of Polystyrene and Poly-R-methylstyrene. Polymer 1993, 34 (7), 1436-1439. 
PlasticsEurope: Plastics-the Facts 2016. 2016/10/20; 534

$<$ http://www.plasticseurope.org/Document/plastics---the-facts-2016-15787.aspx?Fol 535 ID=>. (last accessed 08.02.2017).

Rochman, C.M.; Hoh, E.; Hentschel, B.T.; Kaye, S. Long-Term Field Measurement of Sorption of Organic Contaminants to Five Types of Plastic Pellets: Implications for Plastic Marine Debris. Environ. Sci. Technol. 2013, 47 (3), 1646-1654.

Sato, S.; Murakata, T.; Baba, S.; Saito, Y.; Watanabe, S. Solvent effect on Thermal Degradation of Polystyrene. J. Appl. Polym. Sci. 1990, 40, 2065-2071.

Shah, A.A.; Hasan, F.; Hameed, A.; Ahmed, S. Biological degradation of plastics: A comprehensive review. Biotechnol. Adv. 2008, 26 (3), 246-265.

Sielicki, M.; Focht, D.D.; Martin, J.P. Microbial Degradation of $\left[\mathrm{C}^{14} \mathrm{C}\right]$ polystyrene and 1,3diphenylbutane. Can. J. Microbiol. 1978, 24 (7), 798-803.

Tang, Z.-L.; Kuo, T.-A., Liu, H.-H. The study of the microbes degraded polystyrene. Advance in Technology Innovation. 2017, 2(1), 13-17.

Xu, S.-C.; Tang, T.; Yan, H.;Liu, X.-W. The study on the Tenebrio molitor in the different feed proportions of bubble degradation rate. Journal of Environmental Entomology (in Chinese). 2013, 35(1), 90-94.

Yang, S.-S.; Anja Malawi Brandon, James Christopher Andrew Flanagan, Jun Yang, Daliang Ning, Shen-Yang Cai, Han-Qing Fan, Zhi-Yue Wang, Jie Ren, Eric Benbow, Nan-Qi Ren, Robert M. Waymouth, Jizhong Zhou, Craig S. Criddle, Wei-Min Wu.. Biodegradation of polystyrene wastes in yellow mealworms (larvae of Tenebrio molitor Linnaeus): Factors affecting biodegradation rates and the ability of polystyrene-fed larvae to complete their life cycle. Chemosphere. 2018, 191, 979-989.

Yang, Y.; Yang, J.; Wu, W.M.; Zhao, J.; Song, Y.L.; Gao, L.C.; Yang, R.F.; Jiang, L. Biodegradation and Mineralization of Polystyrene by Plastic-Eating Mealworms: Part 1. Chemical and Physical Characterization and Isotopic Tests. Environ. Sci. Technol. 2015, 49 (20), 12080-12086.

Yang, Y.; Yang, J.; Wu, W.M.; Zhao, J.; Song, Y.L.; Gao, L.C.; Yang, R.F., Jiang, L. Biodegradation and Mineralization of Polystyrene by Plastic-Eating Mealworms: Part 2. Role of Gut Microorganisms. Environ. Sci. Technol. 2015, 49 (20), 12087-12093.

Zia, K.M.; Bhatti, H.N.; Bhatti, I.A. Methods for polyurethane and polyurethane composites, recycling and recovery: a review. React. Funct. Polym. 2007, 67 (8), 675-692. 


\section{Supplementary data}

1. Source of mealworms tested for depolymerization and degradation

Source 1: the PetCo Pet Store Chain, Mountain View, California, the USA (supplied by Timberline Fisheries, Marion, Illinois, the USA)

Source 2: the PetSmart Pet Store Chain, Sunnyvale, California (supplied by Bug Company, Ham Lake, Minnesota, the USA)

Source 3: Timberline Fisheries, Marion, Illinois, the USA

Source 4: Exotic Nutrition Pet Company, Newport News, Virginia, the USA

Source 5: Rainbow Mealworms, Compton, California, the USA

Source 6: A pet store in Belfast, North Ireland, UK

Source 7: A pet store in Beijing, China

Source 8: A store in Harbin, Heilongjiang Province, China

Source 9: A mealworm farm in Tai'an County, Shandong Province, China

Source 10: A pet store in Xi'an City, Shaanxi Province, China

Source 11: A pet store in Shanghai, China

Source 12: A pet store in Shenzhen City, Guangdong Province, China

2. Procedures of molecular analysis

Before DNA from the larvae of Tenebrio molitor was extracted, the external surface of the larvae was disinfected with a $10 \%$ hypochlorite wash followed by a triple rinse in sterile water as previously described (Ridley et al., 2012). Two tissue types were investigated: midgut tissue, which was dissected with sterile instrumentation, and homogenized larvae (with alimentary canal and head removed). DNA extractions of pooled larval midguts $(\mathrm{N}=3$ per sample) and homogenized larvae were performed using the DNeasy Blood and Tissue kit (Qiagen) with addition of lysozyme $\left(15 \mathrm{mg} \mathrm{ml}^{-1}\right.$, Invitrogen) during the lysis step. DNA was quantified using a Qubit dsDNS HS (High Sensitivity) Assay Kit (Invitrogen) and a Qubit 2.0 (Thermo Fisher). All DNA preparations were stored at $-20{ }^{\circ} \mathrm{C}$ until sequencing. Library construction and sequencing ( 2 x 250 bp paired-end reads, Illumina MiSeq) were performed by the Michigan State University Genomics Core Facility using a modified version of the 
protocol adapted for the Illumina MiSeq, described by Caporaso et al. (2011). Regionspecific primers 515F/806R (5'-GTGCCAGCMGCCGCGG-3', 5'-

TACNVGGGTATCTAATCC-3') were used to amplify variable region 4 of the $16 \mathrm{~S}$ rRNA gene according to previously described methods (Claesson et al., 2010; Caporaso et al., 2011). The raw reads were demultiplexed, assembled, and quality-filtered in QIIME 2 (v 2017.12), using default settings (https://qiime2.org) (Kuczynski et al., 2011). DADA2 was used to filter chimeric reads and artifacts commonly present in Illumina amplicon data (Callahan et al., 2016). To classify filtered reads to taxanomic groups, a Naive Bayes classifier was trained using the $16 \mathrm{~S}$ rRNA region (V4), the primer set and read length used (515F/806R, $250 \mathrm{bp})$, and the Greengenes 99\% reference set (v 13.8, http://greengenes.secondgenome.com) (DeSantis et al., 2006; McDonald et al., 2012; Werner et al., 2012). This trained feature classifier was then used to assign taxonomy to each read using the default settings in QIIME. Reads assigned to mitochondria or chloroplast were removed from each sample before analysis. For each taxanomic group at a certain level (e.g. phylum, class, genus, etc.), the relative abundance difference between groups was tested with Wilcoxon rank-sum tests (FDR correction) in R (v 2.4.4) (R Development Core Team R, 2017) and visualized using ggplot2 (v 2.2.1) (Wickham, 2016). 


\section{Supplementary Figures}
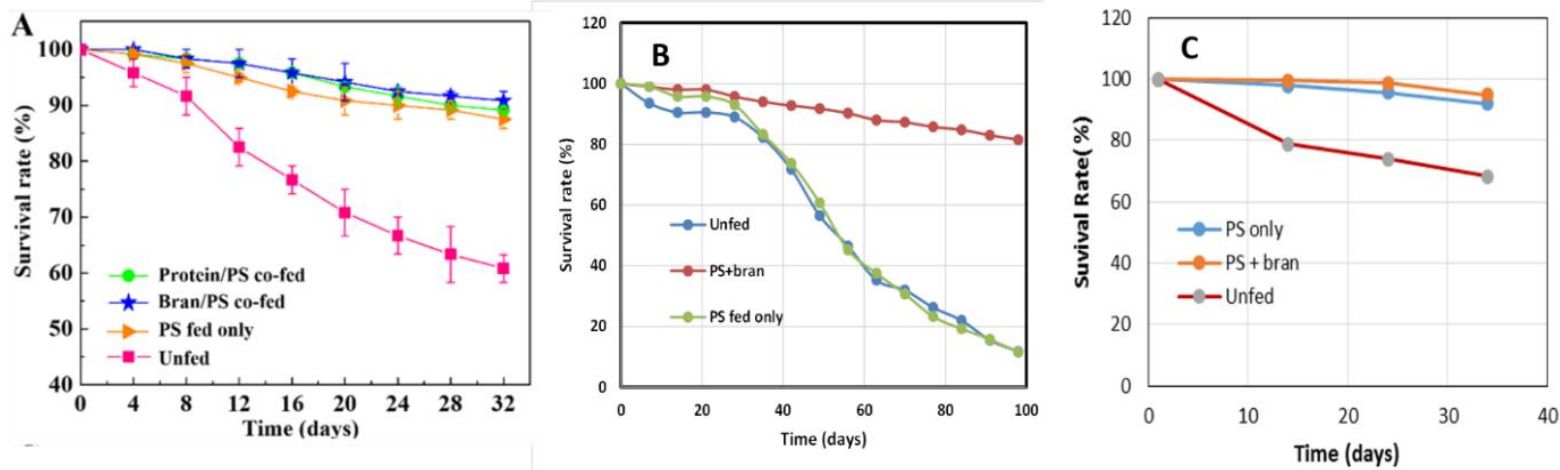

Figure S1. Typical survival curves of mealworms fed with PS only or PS plus bran and unfed. (A) Mealworms from PetCo, USA (source 1) fed with protein plus PS, bran plus PS, PS only versus control (unfed). (B) Mealworms from Belfast, North Orland, UK (source 6) fed with bran plus PS, PS alone, and unfed. (C) Mealworms from Shanghai, China (source 11) fed with PS only and PS plus bran versus control (unfed). Single incubators with 410 mealworms each were used. Note: Figure S1A is adapted from Yang et al. (2018).

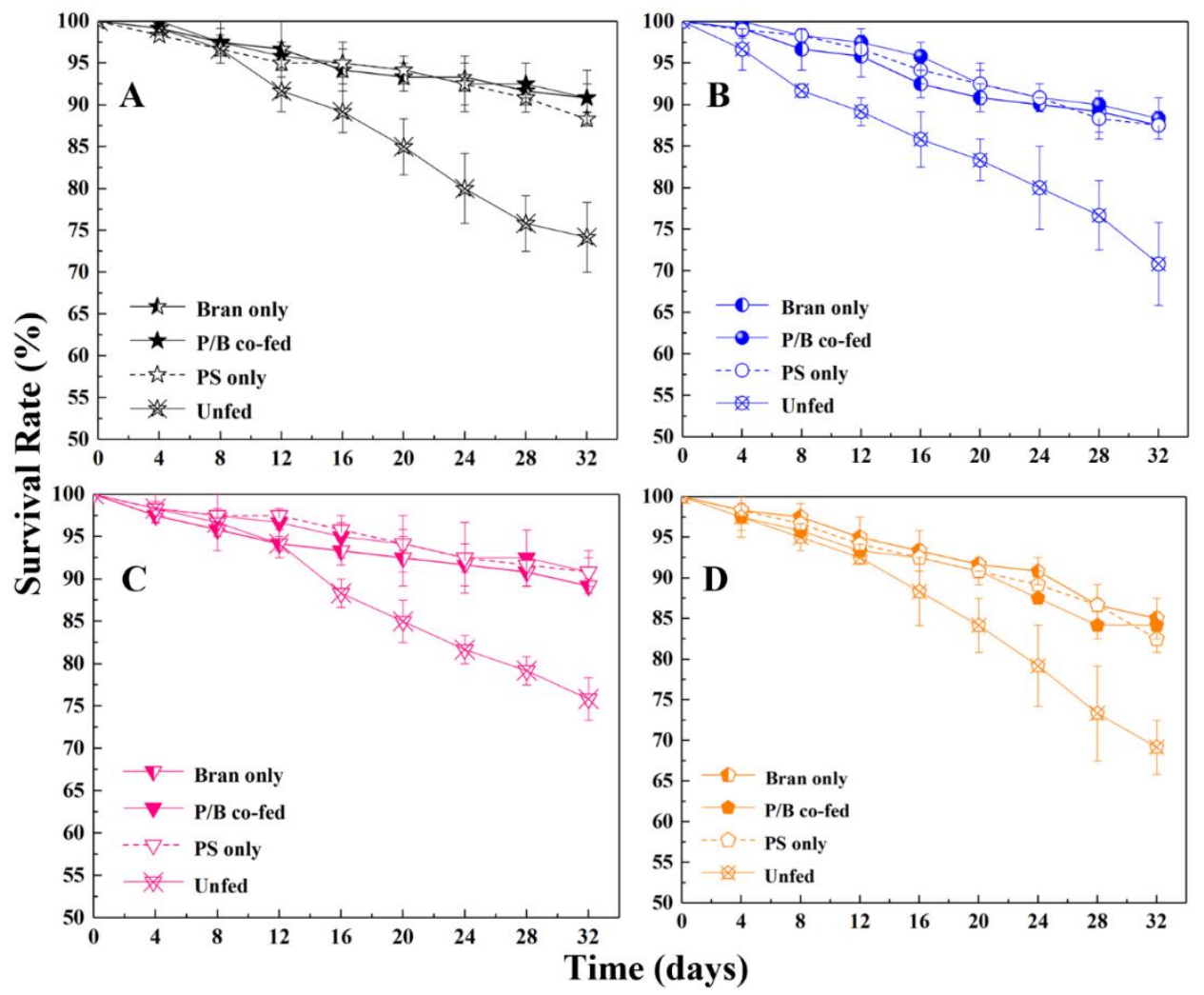

Figure S2. Comparison of survival rate (SR) curves of mealworms fed with bran, PS plus bran, PS only and without feed with mealworms from four USA sources. The tests were performed using mealworms from USA sources 2 (A) , 3 (B), 4(C) and 5(D) at $25^{\circ} \mathrm{C}$. The initial number of mealworms in each incubator was 120 with duplicates. The data showed that the SR curves of mealworms fed with bran, bran plus PS and PS were similar during a 32 day period. The SRs of unfed mealworms of all sources were well below those fed with bran only, PS plus bran (P/B co-fed) and PS only during a 32 day period. 

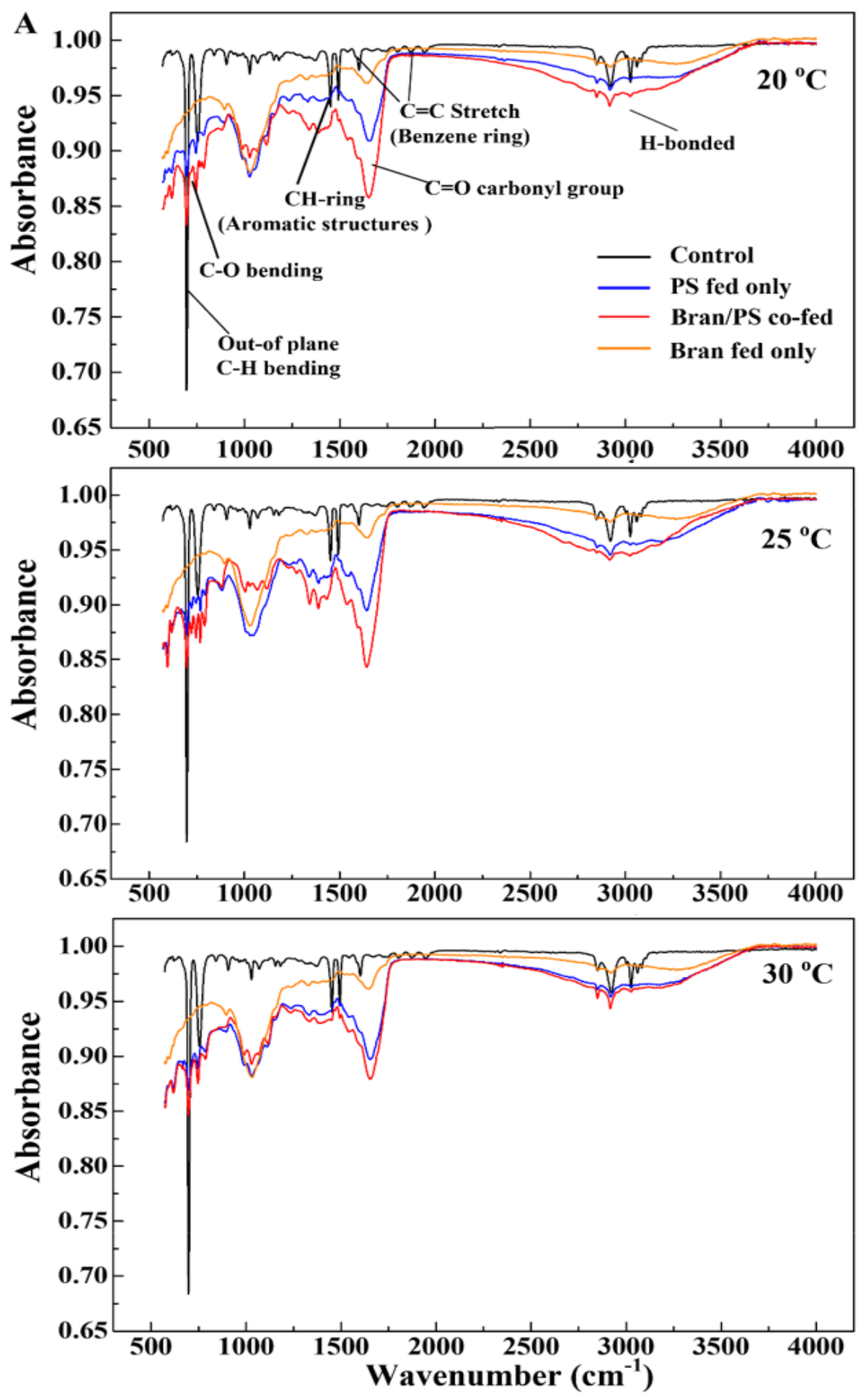

Figure S3. FTIR spectra of feed stock and frass samples of mealworms CP fed bran, PS and bran plus PS at three different temperatures $\left(20,25\right.$ and $\left.30{ }^{\circ} \mathrm{C}\right)$. The results showed that the frass samples of mealworms fed with PS only and PS plus bran showed C-O bending near 800 but the samples fed with bran only did not. Strong $\mathrm{C}=\mathrm{O}$ carbonyl group peak was observed in the samples fed with PS and PS plus bran. The mealworms used was from Source 1. Data from Yang et al. (2018). 

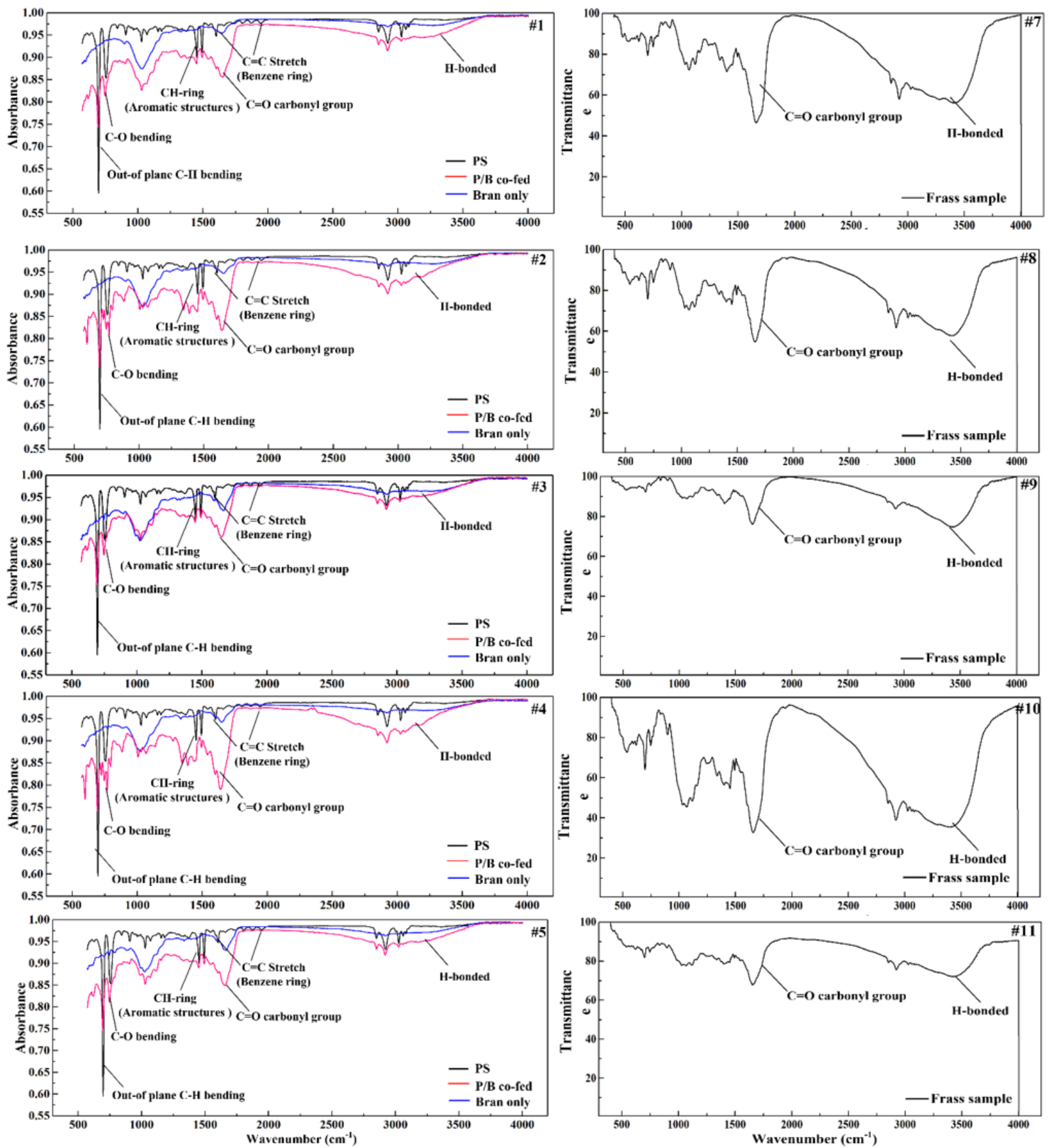

Figure S4. FTIR graphs of mealworm frass fed with PS plus bran from various sources $(1-5,7-11)$, which were similar to those fed with PS plus bran in Figure S3. 


\section{Supplementary Tables}

Table S1. 32 day survival rate (\%) of mealworms fed with bran only, PS plus bran, PS only and unfed from four USA sources

\begin{tabular}{lllll}
\hline Feed & Bran only & PS+Bran co-fed & PS only & Unfed \\
\hline Source 2 & $90.8 \pm 1.7$ & $90.8 \pm 3.3$ & $88.3 \pm 0.8$ & $74.2 \pm 4.2$ \\
Source 3 & $87.5 \pm 1.7$ & $88.3 \pm 2.5$ & $87.5 \pm 1.7$ & $70.8 \pm 5.0$ \\
Source 4 & $89.2 \pm 0.8$ & $90.8 \pm 2.5$ & $90.8 \pm 1.7$ & $75.8 \pm 2.5$ \\
Source 5 & $85.0 \pm 2.5$ & $84.2 \pm 1.7$ & $82.5 \pm 1.7$ & $69.2 \pm 3.3$ \\
\hline
\end{tabular}

Note: Source description in Section 1 SPI. The test condition is described in Fig. S2.

Table S2. Survival rate (\%) and weigh changes of mealworms fed with PS plus bran, PS only and unfed from Shanghai (Source 11)

\begin{tabular}{lllllcccc}
\hline & \multicolumn{2}{c}{ Bran only } & \multicolumn{2}{c}{ PS+Bran } & \multicolumn{2}{c}{ PS only } & \multicolumn{2}{c}{ Unfed } \\
\cline { 2 - 8 } Feed & SG, $\%$ & $\Delta$ weight & SG, $\%$ & $\Delta$ weight, $\%$ & SG, $\%$ & $\Delta$ weight, $\%$ & SG, $\%$ & $\Delta$ weight, $\%$ \\
\hline Day 0 & 100 & 0 & 0 & 0 & 100 & 0 & 100 & 0 \\
Day 14 & 100 & $3.5 \%$ & 99.5 & $0.1 \%$ & 97.8 & $-8.2 \%$ & 78.8 & $-10.2 \%$ \\
Day 24 & nd & $13.0 \%$ & 98.8 & $8.0 \%$ & 95.6 & $-10.4 \%$ & 73.9 & $-13.3 \%$ \\
Day 34 & nd & $25.0 \%$ & 95.0 & $16.0 \%$ & 92.0 & $-9.3 \%$ & 68.3 & $-17.4 \%$ \\
\hline
\end{tabular}

Note: Source description in Section 1 SPI. The test condition is described in Fig. S2C. Test was performed with single incubator with 410 mealworms each. The initial average weight of mealworms was $96.0 \pm 0.6$ $\mathrm{mg} /$ worm. Initially, $4.7 \mathrm{~g}$ of PS foam was added into each container. $8.5 \mathrm{~g}$ of bran was added at the beginning and then supplemented 8.5 every 5 days. A total of 8 times. The mealworms with PS only consumed $2.0 \mathrm{~g} \mathrm{PS}$ while those fed with bran plus PS consumed $2.7 \mathrm{~g}$ PS.

Table S3. Decrease in average molecular weights $\left(\mathrm{M}_{\mathrm{n}}\right.$ and $\left.\mathrm{M}_{\mathrm{w}}\right)$ of residual PS polymers in the frass of mealworms fed bran plus PS

\begin{tabular}{ccccc}
\hline $\begin{array}{c}\text { Source of } \\
\text { mealworms }\end{array}$ & $\mathbf{M}_{\mathbf{n}}$ & $\mathbf{M}_{\mathbf{w}}$ & $\begin{array}{c}\mathbf{M}_{\mathbf{n}} \text { reduction } \\
\text { compared with control } \\
\mathbf{P S}\end{array}$ & $\begin{array}{c}\mathbf{M}_{\mathbf{w}} \text { reduction compared } \\
\text { with control PS }\end{array}$ \\
\hline 1 & $82000 \pm 2000$ & $210000 \pm 1000$ & $9.40 \pm 0.72$ & $7.19 \pm 0.48$ \\
2 & $78000 \pm 2000$ & $200000 \pm 6000$ & $13.58 \pm 3.53$ & $10.78 \pm 2.57$ \\
3 & $78000 \pm 3000$ & $203000 \pm 8000$ & $13.34 \pm 4.61$ & $10.88 \pm 3.24$ \\
4 & $76000 \pm 4000$ & $206000 \pm 4000$ & $15.64 \pm 4.73$ & $10.29 \pm 2.73$ \\
5 & $77000 \pm 2000$ & $204000 \pm 6000$ & $14.27 \pm 0.13$ & $12.10 \pm 4.51$ \\
6 & $84000 \pm 5000$ & $182000 \pm 9000$ & $5.37 \pm 0.19$ & $5.55 \pm 1.12$ \\
7 & $78000 \pm 4000$ & $215000 \pm 3000$ & $12.92 \pm 2.51$ & $6.72 \pm 0.79$ \\
1 & $78000 \pm 2000$ & $212000 \pm 1000$ & $13.50 \pm 4.08$ & $6.50 \pm 2.06$ \\
11 & $82000 \pm 2000$ & $213000 \pm 6000$ & $9.05 \pm 0.18$ & $5.89 \pm 1.28$ \\
12 & $81000 \pm 4000$ & $214000 \pm 3000$ & $9.53 \pm 2.17$ & $5.18 \pm 1.72$ \\
& $77000 \pm 2000$ & $216000 \pm 3000$ & $14.08 \pm 1.48$ & $9.02 \pm 1.09$ \\
\hline
\end{tabular}

Locations of numbered sources are provided in the main text. Molecular weights for PS from different sources: for sources $1-5,7-11, M_{n}$ was $90000 \pm 2000$, and $M_{w}$ was $228000 \pm 12000$; source $6, M_{n}$ was $89000 \pm 2000$, and $M_{w}$ was $207000 \pm 2000$; for source $12, M_{n}$ was $93000 \pm 3000$, and $M_{w}$ was $254000 \pm 1000$. 
Table S4 T-test comparing $M_{n}$ and $M_{w}$ of PS feedstock to $M_{n}$ and $M_{w}$ values of residual polymer in the frass of mealworms from the 12 sources when fed both bran and PS

\begin{tabular}{cccccccc}
\hline Feedstock & $\begin{array}{c}\text { Residual PS } \\
\text { in frass from } \\
\text { mealworm } \\
\text { source }\end{array}$ & Value & $\begin{array}{c}\boldsymbol{p} \text { - } \\
\text { value* }\end{array}$ & $\begin{array}{c}\text { Significance } \\
\text { (Y/N) }\end{array}$ & $\begin{array}{c}\boldsymbol{p} \text { - } \\
\text { Value }\end{array}$ & $\begin{array}{c}\text { Significance } \\
\text { value* }\end{array}$ \\
\hline $\mathrm{A}$ & 1 & $\mathrm{M}_{\mathrm{n}}$ & 0.0025 & $\mathrm{Y} / \mathrm{N})$ & $\mathrm{M}_{\mathrm{w}}$ & 0.0017 & $\mathrm{Y}$ \\
$\mathrm{A}$ & 2 & $\mathrm{M}_{\mathrm{n}}$ & 0.0241 & $\mathrm{Y}$ & $\mathrm{M}_{\mathrm{w}}$ & 0.0184 & $\mathrm{Y}$ \\
$\mathrm{A}$ & 3 & $\mathrm{M}_{\mathrm{n}}$ & 0.0400 & $\mathrm{Y}$ & $\mathrm{M}_{\mathrm{w}}$ & 0.0279 & $\mathrm{Y}$ \\
$\mathrm{A}$ & 4 & $\mathrm{M}_{\mathrm{n}}$ & 0.0307 & $\mathrm{Y}$ & $\mathrm{M}_{\mathrm{w}}$ & 0.0166 & $\mathrm{Y}$ \\
$\mathrm{A}$ & 5 & $\mathrm{M}_{\mathrm{n}}$ & 0.0003 & $\mathrm{Y}$ & $\mathrm{M}_{\mathrm{w}}$ & 0.0231 & $\mathrm{Y}$ \\
$\mathrm{B}$ & 6 & $\mathrm{M}_{\mathrm{n}}$ & 0.0450 & $\mathrm{Y}$ & $\mathrm{M}_{\mathrm{w}}$ & 0.0069 & $\mathrm{Y}$ \\
$\mathrm{A}$ & 7 & $\mathrm{M}_{\mathrm{n}}$ & 0.0103 & $\mathrm{Y}$ & $\mathrm{M}_{\mathrm{w}}$ & 0.0132 & $\mathrm{Y}$ \\
$\mathrm{A}$ & 8 & $\mathrm{M}_{\mathrm{n}}$ & 0.0322 & $\mathrm{Y}$ & $\mathrm{M}_{\mathrm{w}}$ & 0.0049 & $\mathrm{Y}$ \\
$\mathrm{A}$ & 9 & $\mathrm{M}_{\mathrm{n}}$ & 0.0005 & $\mathrm{Y}$ & $\mathrm{M}_{\mathrm{w}}$ & 0.0311 & $\mathrm{Y}$ \\
$\mathrm{A}$ & 10 & $\mathrm{M}_{\mathrm{n}}$ & 0.0140 & $\mathrm{Y}$ & $\mathrm{M}_{\mathrm{w}}$ & 0.0158 & $\mathrm{Y}$ \\
$\mathrm{A}$ & 11 & $\mathrm{M}_{\mathrm{n}}$ & 0.0036 & $\mathrm{Y}$ & $\mathrm{M}_{\mathrm{w}}$ & 0.0356 & $\mathrm{Y}$ \\
$\mathrm{C}$ & 12 & $\mathrm{M}_{\mathrm{n}}$ & 0.0079 & $\mathrm{Y}$ & $\mathrm{M}_{\mathrm{w}}$ & 0.0051 & $\mathrm{Y}$ \\
\hline
\end{tabular}

* The results indicated that the changes in molecular weights were significant. See text for feedstock sources and mealworm source locations.

Table S5 Number of total visible gut bacteria counted from the control mealworms and the antibiotic treated mealworms. Mealworms from the five USA sources were assayed after continuous feeding of gentamicin for 7 days

\begin{tabular}{ccc}
\hline Sources of & \multicolumn{2}{c}{ Gut Bacteria Concentration (CFUs per gut) } \\
\cline { 2 - 3 } mealworms & Control tests & Antibiotic treatment tests \\
\hline USA source 1 & $(4.79 \pm 0.31) \times 10^{6}$ & $(1.91 \pm 8.56) \times 10^{4}$ \\
USA source 2 & $(6.89 \pm 0.21) \times 10^{5}$ & $(5.67 \pm 0.98) \times 10^{3}$ \\
USA source 3 & $(3.46 \pm 0.18) \times 10^{6}$ & $(1.64 \pm 0.13) \times 10^{4}$ \\
USA source 4 & $(5.01 \pm 0.17) \times 10^{6}$ & $(1.27 \pm 0.16) \times 10^{5}$ \\
USA source 5 & $(2.23 \pm 0.25) \times 10^{6}$ & $(6.22 \pm 0.61) \times 10^{4}$ \\
\hline
\end{tabular}

Table S6 The molecular weights $\left(M_{n}\right.$ and $\left.M_{w}\right)$ of the PS and the frass samples from 5 USA sources after feeding with gentamicin for 15 days

\begin{tabular}{ccc}
\hline Sample & $\mathbf{M}_{\mathbf{n}}$ & $\mathbf{M}_{\mathbf{w}}$ \\
\hline PS feedstock & $90000 \pm 2000$ & $228000 \pm 1000$ \\
Frass from source 1 & $88000 \pm 2000$ & $223000 \pm 4000$ \\
Frass from source 2 & $87000 \pm 2000$ & $223000 \pm 3000$ \\
Frass from source 3 & $85000 \pm 3000$ & $224000 \pm 5000$ \\
Frass from source 4 & $85000 \pm 1000$ & $225000 \pm 3000$ \\
Frass from source 5 & $85000 \pm 2000$ & $226000 \pm 4000$ \\
\hline
\end{tabular}


Table S7 T-test statistical analysis of $\mathrm{M}_{\mathrm{n}}$ and $\mathrm{M}_{\mathrm{w}}$ of PS feedstock versus residual polymer extracted from frass samples of the mealworms previously fed gentamicin and receiving a diet of bran plus PS.

\begin{tabular}{|c|c|c|c|c|c|c|c|c|c|}
\hline Value & $\begin{array}{c}\text { Sample } \\
1\end{array}$ & $\begin{array}{c}\text { Sample } \\
2\end{array}$ & $p$-value & $\begin{array}{c}\text { Significance } \\
\qquad(\mathrm{Y} / \mathrm{N})\end{array}$ & Value & $\begin{array}{c}\text { Sample } \\
1\end{array}$ & $\begin{array}{c}\text { Sample } \\
2\end{array}$ & $p$-value & $\begin{array}{c}\text { Significance } \\
(\mathbf{Y} / \mathbf{N})\end{array}$ \\
\hline$M_{n}$ & PS & Frass 1 & 0.3502 & $\mathrm{~N}$ & $\mathrm{M}_{\mathrm{w}}$ & PS & Frass 1 & 0.2325 & $\mathrm{~N}$ \\
\hline $\mathrm{M}_{\mathrm{n}}$ & PS & Frass 2 & 0.2545 & $\mathrm{~N}$ & $\mathrm{M}_{\mathrm{w}}$ & PS & Frass 2 & 0.0629 & $\mathrm{~N}$ \\
\hline $\mathrm{M}_{\mathrm{n}}$ & PS & Frass 3 & 0.2622 & $\mathrm{~N}$ & $\mathrm{M}_{\mathrm{w}}$ & PS & Frass 3 & 0.1842 & $\mathrm{~N}$ \\
\hline $\mathrm{M}_{\mathrm{n}}$ & PS & Frass 4 & 0.0565 & $\mathrm{~N}$ & $\mathrm{M}_{\mathrm{w}}$ & PS & Frass 4 & 0.2730 & $\mathrm{~N}$ \\
\hline $\mathrm{M}_{\mathrm{n}}$ & PS & Frass 5 & 0.0769 & $\mathrm{~N}$ & $\mathrm{M}_{\mathrm{w}}$ & PS & Frass 5 & 0.7133 & $\mathrm{~N}$ \\
\hline $\mathrm{M}_{\mathrm{n}}$ & 1 & Frass 1 & 0.0378 & $\mathrm{Y}$ & $\mathrm{M}_{\mathrm{w}}$ & $\mathrm{F}_{1}-\# 1$ & Frass 1 & 0.0282 & $\mathrm{Y}$ \\
\hline $\mathrm{M}_{\mathrm{n}}$ & 2 & Frass 2 & 0.0027 & $\mathrm{Y}$ & $\mathrm{M}_{\mathrm{w}}$ & $\mathrm{F}_{1}-\# 2$ & Frass 2 & 0.0140 & $\mathrm{Y}$ \\
\hline $\mathrm{M}_{\mathrm{n}}$ & 3 & Frass 3 & 0.0287 & $\mathrm{Y}$ & $\mathrm{M}_{\mathrm{w}}$ & $\mathrm{F}_{1}-\# 3$ & Frass 3 & 0.0228 & $\mathrm{Y}$ \\
\hline $\mathrm{M}_{\mathrm{n}}$ & 4 & Frass 4 & 0.0383 & Y & $\mathrm{M}_{\mathrm{w}}$ & $\mathrm{F}_{1}-\# 4$ & Frass 4 & 0.0182 & $\mathrm{Y}$ \\
\hline$M_{n}$ & 5 & Frass 5 & 0.0300 & $\mathrm{Y}$ & $\mathrm{M}_{\mathrm{w}}$ & $\mathrm{F}_{1}$-\#5 & Frass 5 & 0.0281 & Y \\
\hline
\end{tabular}

The results indicated no significant differences between PS feedstock versus residual PS polymers of the frass from mealworms fed gentamicin. Significant differences were observed between the residual polymers with and without gentamicin in the feed.

\section{References}

Caporaso, J.G., Lauber, C.L., Costello, E.K., Berg-Lyons, D., Gonzalez, A., Stombaugh, J., Knights, D., Gajer, P., Ravel, J., Fierer, N., Gordon, J.I., Knight, R., 2011. Moving pictures of the human microbiome. Genome Biol. 12, (5), R50.

Caporaso, J.G., Lauber, C.L., Walters, W.A., Berg-Lyons, D., Lozupone, C.A., Turnbaugh, P.J., Fierer, N., Knight, R., 2011. Global patterns of 16S rRNA diversity at a depth of millions of sequences per sample. Proc. Natl. Acad. Sci. U S A 108, (Supplement_1), 4516-4522.

Callahan, B.J., McMurdie, P.J., Rosen, M.J., Han, A.W., Johnson, A.J., Holmes, S.P., 2016. DADA2: High-resolution sample inference from Illumina amplicon data. Nat. methods $13,(7), 581-583$.

Claesson, M.J., Cusack, S., O'Sullivan, O., Greene-Diniz, R., de Weerd, H., Flannery, E., Marchesi, J.R., Falush, D., Dinan, T., Fitzgerald, G., Stanton, C., van Sinderen, D., O'Connor, M., Harnedy, N., O'Connor, K., Henry, C., O'Mahony, D., Fitzgerald, A.P., Shanahan, F., Twomey, C., Hill, C., Ross, R.P., O'Toole, P.W., 2010. Composition, variability, and temporal stability of the intestinal microbiota of the elderly. Proc. Natl. Acad. Sci. U S A 108, Suppl 1 (11): 4586-4591.

DeSantis, T.Z., Hugenholtz, P., Larsen, N., Rojas, M., Brodie, E.L., Keller, K., Huber, T., Dalevi, D., Hu, P., Andersen, G.L., 2006. Greengenes, a chimera-checked 16S rRNA 
gene database and workbench compatible with ARB. Appl. Environ. Microbiol. 50695072.

Kuczynski, J., Stombaugh, J., Walters, W. A., González, A., Caporaso, J. G., Knight, R., 2011. Using QIIME to analyze 16S rRNA gene sequences from Microbial Communities. Current protocols in bioinformatics / editoral board, Andreas D. Baxevanis ... [et al.] CHAPTER, Unit10.7-Unit10.7.

McDonald, D., Price, M.N., Goodrich, J., Nawrocki, E.P., DeSantis, T.Z., Probst, A., Andersen, G.L., Knight, R., Hugenholtz, P., 2012. An improved Greengenes taxonomy with explicit ranks for ecological and evolutionary analyses of bacteria and archaea. Isme J. 6, (3), 610-618.

R Development Core Team R: A language and enviornment for statistical computing, 2.4.4; R Foundation for Statistical Computing: Vienna, Austria, 2017.

Ridley, E. V., Wong, A. C. N., Westmiller, S., Douglas, A. E., 2012. Impact of the Resident Microbiota on the Nutritional Phenotype of Drosophila melanogaster. PLOS ONE 7, (5), e36765.

Werner, J.J., Koren, O., Hugenholtz, P., DeSantis, T.Z., Walters, W.A., Caporaso, J.G., Angenent, L.T., Knight, R., Ley, R.E., 2012. Impact of training sets on classification of high-throughput bacterial 16s rRNA gene surveys. Isme J. 6, (1), 94-103.

Wickham, H., 2016. ggplot2: elegant graphics for data analysis. Springer.

Yang, S.S., Brandon, A.M., Flanagan, J.C.A., Yang, J., Ning, D.L., Cai, S.Y., Fan, H.Q., Wang, Z.Y., Ren, J., Benbow, E., Ren, N.Q., Waymouth, R.M., Zhou, J.Z., Criddle, C.S., Wu, W.M., 2018. Biodegradation of polystyrene wastes in yellow mealworms (larvae of Tenebrio molitor Linnaeus): Factors affecting biodegradation rates and the ability of polystyrene-fed larvae to complete their life cycle. Chemosphere. 191, 979-989. 